\title{
Standardized Environmental Management Systems as an Internal Management Tool*
}

\author{
Eduard Alonso ${ }^{\dagger} \quad$ Francisco J. André ${ }^{\ddagger}$
}

November 4, 2014

\begin{abstract}
In a principal-agent model we analyze the firm's decision to adopt an informal or a standardized Environmental Management System (EMS). Our results are consistent with empirical evidence in several respects. A standardized EMS increases the internal control at the cost of introducing some degree of rigidity that entails an endogenous setup cost. Standardized systems are more prone to be adopted by big and well established firms and under tougher environmental policies. Firms with standardized EMS tend to devote more effort to abatement although this effort results in lower pollution only if public incentives are strong enough, suggesting a complementarity relationship between standardized EMS and public policies. Emission charges have both a marginal effect on abatement and a qualitative effect on the adoption decision that may induce a conflict between private and public interests. As a result of the combination of these two effects it can be optimal for the government to distort the tax in a specific way in order to push the firm to choose the socially optimal EMS. The introduction of standardized systems can result in win-win situations where firms, society and the environment get better off.
\end{abstract}

Keywords: Environmental Management System, Asymmetric Information, Emission Charges, Principal-Agent Model.

JEL codes: Q58, D82, L51

${ }^{*}$ We acknolwledge useful comments by Inés Macho-Stadler, David Pérez-Castrillo, Nicolás Porteiro, Ramón Valle, Francisco Carrasco, Aleix Calveras, Lluís Bru, Diego Martínez, Antonio J. Sánchez-Fuentes, Cristina Mazón, Ester Camiña, Francisco Alvarez, Bernard Sinclair-Desgagné and two anonymous referees, as well as the members of the Department of Applied Economics at the University of Valladolid, and the participants in the VII conference of the Spanish Association for Energy Economics, the 38th EARIE conference and the XXVI Jornadas de Economia Industrial. We acknowledge financial support from research projects ECO2008-04321/ECON and ECO2012-39553-C04-01 (Spanish Ministry of Science and European Regional Development Fund, ERDF), SEJ 04992 and SEJ-6882 (Andalusian regional government).

${ }^{\dagger}$ Universitat de les Illes Balears. Departament d'economia de l'empresa. Campus Cra. Valldemossa, Km. 7. 07122. Palma de Mallorca (Spain). E-mail: eduard.alonso@uib.es.

${ }^{\ddagger}$ CORRESPONDING AUTHOR. Universidad Complutense de Madrid. Department of Economic Analysis. Campus de Somosaguas. 28223 Madrid (Spain). E-mail: andre@ccee.ucm.es. 


\title{
Standardized Environmental Management Systems as an Internal Management Tool
}

\author{
November 4, 2014
}

\begin{abstract}
In a principal-agent model we analyze the firm's decision to adopt an informal or a standardized Environmental Management System (EMS). Our results are consistent with empirical evidence in several respects. A standardized EMS increases the internal control at the cost of introducing some degree of rigidity that entails an endogenous setup cost. Standardized systems are more prone to be adopted by big and well established firms and under tougher environmental policies. Firms with standardized EMS tend to devote more effort to abatement although this effort results in lower pollution only if public incentives are strong enough, suggesting a complementarity relationship between standardized EMS and public policies. Emission charges have both a marginal effect on abatement and a qualitative effect on the adoption decision that may induce a conflict between private and public interests. As a result of the combination of these two effects it can be optimal for the government to distort the tax in a specific way in order to push the firm to choose the socially optimal EMS. The introduction of standardized systems can result in win-win situations where firms, society and the environment get better off.
\end{abstract}

Keywords: Environmental Management System, Asymmetric Information, Emission Charges, Principal-Agent Model.

JEL codes: Q58, D82, L51

\section{Introduction}

An Environmental Management System (EMS) can be defined as "the part of the overall management system that includes organizational structure, planning activities, responsibilities, practices, procedures, processes and resources for developing, implementing, achiev- 
ing, reviewing and maintaining the environmental policy" (ISO 14001, 1996). An increasing number of firms are opting to conform their EMS to international standards such as the European Eco-management and Audit Scheme (EMAS) and especially the world-wide standard ISO 14001.

Boiral (2007) suggests two roles of a corporate EMS: first, it can be seen as a way of publicizing an organization's legitimacy among various stakeholders -especially if it is certified according to an international standard- and second, it can be seen as an internal management tool. Instead of analyzing the publicity effect, that has already been addressed in the literature (see e.g. Johnstone and Labonne, 2009) we focus on the second effect, i.e., the role of an EMS as an internal management tool. One essential feature of an EMS is its voluntary nature, in the sense that its adoption is not imposed by the government, but is a free decision of the firm. This paper presents a theoretical analysis of the firm's decision to adopt an EMS and the choice between a standardized EMS and an informal one, focusing on the internal organization aspects. It also explores the interactions of these decisions with environmental regulation.

The main aspect we want to emphasize is the fact that a standardized EMS improves internal control at the cost of introducing a certain degree of rigidity. We do so by building a theoretical model of a firm that needs to curb its emissions while facing an uncertain environment as well as an internal agency problem. We assume that pollution reduction can be undertaken in two polar ways: one characterized by imperfect internal control (due to information asymmetry) but higher flexibility, and other one providing a better internal control by giving up some flexibility.

The first option is to implement some ad-hoc system (labeled as Informal) by contracting an expert (the "manager") and giving him the freedom to make the abatement 
decisions. The advantage of this approach is that the expert is able to make quicker decisions without being constrained by a established protocol. The drawback is that the firm loses some control and needs to trust the manager, who is more informed than the firm. We capture this idea by assuming that effort is a discretional decision of the manager not observed by the firm. This situation entails an asymmetric information problem and, hence, an incentive scheme is required.

The second option is what we call a Standardized EMS (like EMAS or ISO 14001). As Bansal and Bogner (2002) stress "ISO 14001 does not set performance standards. Instead, ISO 14001 focuses on management processes rather than specific environmental outcomes" (p. 271). Accordingly, we associate a standardized EMS not to a specific environmental outcome, but to a certain set of practices, which in our model corresponds to a given level of abatement effort. We model the idea that a standardized EMS provides a very structured procedure that gives the firm more internal control by assuming that effort becomes observable and can be specified in the contract. The disadvantage of this option is that making changes is now more costly because any modification of the protocol must follow a more or less rigid procedure and involves a certain amount of paperwork. We simplify this fact by assuming that effort has to be decided before the uncertainty is revealed and cannot be modified afterwards.

We explore the pros and cons of each type of EMS at the organizational level and the connections with public policy. Our most important results are the following. First, those firms adopting a standardized EMS tend to make more abatement effort, which is consistent with the common belief that such firms are somewhat greener. But we also conclude that this higher abatement effort results in lower (expected) emissions only if the incentives provided by public policy are strong enough, which suggests a complementarity between 
standardized systems and environmental economic policies; and this is our second central finding. This complementarity is reinforced by the fact that standardized systems are more prone to be adopted under tougher public policies. Third, a standardized EMS is more likely to be adopted by well established firms, subject to a lower level of uncertainty. Our fourth insight is that standardized systems tend to be subject to an endogenous adoption cost higher than that of informal systems, which seems to be in line with reality.

We also get some insights about public environmental policy in connection to the EMS adoption decision. First, we point out the possible existence of conflicts between private and social interests in the sense that firms might have incentives to adopt an EMS that is not socially optimal, and we analyze how to deal with these conflicts. The most notable finding in this respect is that, under optimal taxation, big or highly pollutant firms are more prone to adopt standardized systems, perhaps more than what is social desirable, and the other way around for small firms. Our final insight is that, under some circumstances, the introduction of standardized EMS results in a win-win-win situation. In particular, we identify conditions under which making available the possibility to implement a standardized EMS reduces both social and firms' costs as well as environmental impact, along with a tax cut.

Several empirical studies have investigated the motivations of firms to adapt and certify their EMS according to EMAS or ISO 14001 (Nakamura et al., 2001, Morrow and Rondinelly 2002, Chan and Wong 2006). These studies identify some "external" motivators such as consumers' pressure or satisfying legal requirements. For our work it is more relevant a second set of "internal" motivators. Many firms report that implementing a standardized EMS introduces some organizational discipline and results in efficiency improvements, cost reductions and, to some extent, it can make the firm work better. In a 
study conducted by the University of North Carolina and the Environmental Law Institute among 50 private and public facilities in the U.S., apart from improving regulatory compliance or customer pressures, the strongest motivators for EMS standardization were internal: to integrate pollution prevention programs, improve environmental capability and enhance employee participation in environmental management activities (UNC_ELI, 2001). In a large-scale survey of companies adopting EMS in Pennsylvania, "corporate goals and objectives" and "economic benefits and improved business performance" where reported among the most important motivators to adopt an EMS (Florida and Davidson 2001, page 67). Pedersen (2007) identifies cost savings both as a relevant driver and an important benefit of adopting EMAS.

Several authors point out the existence of information asymmetries associated to pollution control activities (see, e.g., Gabel and Sinclair-Desgagné 1993, Sinclair-Desgagné and Gabel 1997, Goldsmith and Basak 2001, Ambec and Barla 2002). Johnstone and Labonne (2009) note that "environmental management systems and tools may help managers identify and implement the most cost-effective means of meeting their environmental objectives, allowing for improved performance ... by generating information about both regulatory requirements and internal environmental practices; by helping to resolve internal agency control issues which may result in adverse environmental impacts" (p. 721). Goldsmith and Basak (2001) state that behavioral uncertainties about employee actions are the key to successful EMS implementation (p. 260). These references support our claim that a very structured procedure, such as EMAS or ISO 14001, can increase the level of control of the firm and result in improved managerial efficiency.

Another central point of this article is the existence of some rigidity related to a standardized EMS. As an advantage of standardized EMS versus command-and-control poli- 
$\operatorname{cies}^{1}$, it has been argued that it is a voluntary approach that gives the companies the flexibility to develop systems that are appropriate to their operations, characteristics, location and levels of risk (Rondinelli and Vastag, 1996). But, on the other hand, it has also been argued that adopting a standardized EMS can imply some rigidities since it requires a very structured set of procedures and paperwork at every step of the system. Honkasalo (1998) states that "The rigidity of the EMAS scheme and the complicated language of the text of the regulation can produce difficulties for the firms and hinder them from applying the system in a creative way" (p. 124). Bansal and Bogner (2002) report that certifying an EMS for ISO 14001 is neither easy nor cheap. For example, the Niagara Mohawk Power Station spent six person-months developing its EMS and another 700 hours preparing for certification. Estimates of the financial cost of certification vary widely, from US $\$ 10,000$ (for smaller, stand-alone sites) to US\$200,000 (for large industrial sites). On top of the cost of certification, firms must assume the annual costs of maintaining the documentation. The Global Environmental Technology Foundation has estimated the cost of auditing and paperwork to be US\$ 5,000 to US\$ 10,000 annually per facility. Escapa-González (2004) identifies bureaucratic work as the main barrier to implement an EMS. Consistent with these studies, our claim is that, although a standardized EMS gives the firm more flexibility than a command-and-control policy, it implies giving up some flexibility as compared to "informal" EMS developed ad-hoc for the firm without any pre-established pattern.

From a theoretical perspective, this paper mainly builds on the principal-agent literature. We address the firm's dilemma of delegating a task and providing incentives (what in our framework corresponds to an informal EMS) or keeping that task centralized (which

\footnotetext{
${ }^{1}$ Following standard terminology, by command-and-control policies we refer to direct regulation that determines allowed and prohibited practices. Important examples include effluent standards or technological standards. See, for example, Helfand et al. (2003), p. 275. Sometimes, command-and-control policies are simply called "standards". We avoid this terminology to prevent confusion with the standardized EMS.
} 
corresponds to the adoption of a Standardized EMS). Aghion and Tirole (1997), Dessein (2002) or Stein (2002) focus on delegation under costly communication but do not pay much attention to monetary incentives and effort choice, which are central elements of our study. A closer approach to ours is followed by Prendergast (2002), in which both delegation and provision of monetary incentives are analyzed at the same time. Different from that research, we focus on the firm's decision to adopt an EMS, and the interplay between firm and regulator's decisions.

Our work is also related to the literature on measuring agent's performance based both on input and output measure. In this respect, see Weitzman (1974), Baker (1992), Prendergast (2002) or Raith (2008) as key references. Alonso-Paulí and Pérez-Castrillo (2012) analyze the presence of Codes of Best Practice as a mechanism that allows to monitor the manager's activities while generating a lack of flexibility in the manager's decision making. A central message of this literature is that input measures do not give incentives to use private information (or "specific knowledge") but minimizes agent's income risk, whereas output-based compensation gives incentive to use that information at the cost of a higher income risk. Finally, our paper is also related to the literature on the efficiency of information systems. Adopting either an informal or a Standard EMS is similar to choosing between two different information systems: one involving incentives on output measures in which the agent has more discretion to use his specific knowledge and another one based on input measures, which is more rigid but the firm do not suffer from manager's discretion since the manager cannot use his specific knowledge. For the case of a risk averse agent, see Kim (1995), Demougin and Fluet (2001a) or Fagart and Sinclair-Desgagné (2007). For a risk-neutral agent, which is closer to our approach, see Demougin and Fluet (1998, 2001b).

As far as we know, there are no other papers analyzing EMS adoption in a principal- 
agent model. Actually, we are aware of almost no theoretical articles addressing the firm's adoption decision. Johnstone et al. (2007) present a graphical cost-benefit model of abatement and management decisions but there is not an analytical modelling of the internal management processes of the firm. Goldsmith and Basak (2001) represent an EMS in a model that is similar to ours but they do not address the adoption decision or the connection of such adoption with environmental regulation.

The rest of the paper is structured as follows. Section 2 presents the main elements of the model. Section 3 studies the design of contracts under both systems and the firm's decision between them. Section 4 addresses public policy in connection to firm's adoption decisions. Section 5 summarizes our main policy implications and reviews the empirical relevance of our predictions. Section 6 concludes and offers some guidelines for future developments.

\section{The Model}

\subsection{Basic elements}

A firm's emissions flow is denoted by $P$. In the absence of abatement activities, emissions equal $A$, which is a firm-specific value understood as the business-as-usual (BAU) or maximum level of emissions. $A$ can be seen as a measure of the firm's polluting flow, and hence, the severity of the environmental problem that we are facing. A summarizes all those factors that have an influence on the size of the BAU flow of emissions, such as the size of the firm (ceteris paribus, bigger firms tend to pollute more), the pollution intensity per unit of output of the activities developed by each firm ( $A$ tends to be higher for those firms in highly polluting sectors) and the technological and internal efficiency of the firms 
(more efficient firms tend to pollute less). ${ }^{2}$

Emissions can be reduced by some abatement activities developed by a manager who exerts some effort, e. To capture the imperfect information problem, we assume that the effectiveness of abatement effort is affected by a random shock $\widetilde{x}{ }^{3}$ that ranges between 0 and an upper bound $\bar{x}>0$. This shock represents uncertainty due to environmental, market or technical conditions. The resulting level of emissions is given by

$$
\widetilde{P}=A-e \widetilde{x}
$$

where realized emissions, $P$, are verifiable ex post. Emissions $P$ causes a damage $D(P)$, given by ${ }^{4}$

$$
D(P)=\frac{\delta}{2} P^{2}
$$

where $\delta$ measures the importance of pollution. Moreover, we assume that emissions are subject to a per-unit tax equal to $t$. Thus, $t P$ represents the tax bill of a firm whose emissions are $P$. The tax revenue is redistributed to the society by a lump-sum transfer. ${ }^{5}$

The firm's aim is to minimize his total expected costs $E C$, where $C=t P+w$ includes the tax bill and the manager's salary, $w$, if the manager is contracted. The manager's

\footnotetext{
${ }^{2}$ In some parts of the paper it will be useful to refer to A simply as "size", but what matters for our analysis is not the size of output but the size of the emissions flow.

${ }^{3} \mathrm{~A}$ tilde denotes a stochastic variable and the same symbol without the tilde represents a realization of that variable.

${ }^{4}$ The fact that the damage function is quadratic rather than linear accounts for the fact that typically marginal damage is increasing with the level of emissions. If one focuses on a specific firm, this second-order effect tends to be more relevant the bigger is the firm with respect to the whole size of the environmental problem (e.g., local rather than global pollutants). Alternatively, we can also think of a representative firm in an activity sector rather than an isolated firm.

${ }^{5}$ We need to acknowledge that pollution entails some cost for the firm but part of our discussion is compatible with other interpretations for this cost different from a tax. $t$ can also be interpreted as the price of emission permits in a cap-and-trade system if the firm is as a price taker or the probability to be fined for non-compliance. This cost can also obey to other factors such as firm image, consumers' pressure, the difficulties to trade with some partners or participate in a competitive tender.
} 
utility is given by $u(w, e)=w-c(e)$, being $c(e)=c \frac{e^{2}}{2}$ the cost of effort, and he will not accept a contract that provides him an expected utility lower than his reservation value $\underline{U}$. This condition is the so-called Participation Constraint (PC). Formally,

$$
E u(w, e) \geq \underline{U}
$$

The manager is endowed with a limited liability constraint (LLC), which implies that no negative transfers are allowed. Formally,

$$
w \geq 0 \text { for all } x \in[0, \bar{x}]
$$

As usual in principal-agent models, we assume that the manager has some specific knowledge, which means that he is more informed than the firm about the development of his tasks (see Jensen and Mecking, 1992 and Raith, 2008). We do so by assuming that the manager has more information about the value of $x$. Specifically, we assume that both the manager and the firm know the distribution function $F(x)$, but only the manager can observe the ex-post realization of $x$ and only after he accepts the contract. This is to capture the fact that both are subject to some uncertainty when they sign the contract but, afterwards, the manager has more control over his tasks than the firm. ${ }^{6} \mu \equiv \int_{0}^{\bar{x}} x d F(x)$ denotes the mean, $\sigma^{2} \equiv \int_{0}^{\bar{x}}(x-\mu)^{2} d F(x)$ the variance, $\sigma$ the standard deviation and $\rho \equiv \frac{\sigma}{\mu}$ the coefficient of variation of $\widetilde{x}$. We do not impose any specific distribution function.

\footnotetext{
${ }^{6}$ It is not necessarily the case that the manager is better informed than the firm about random events. What we claim is that the manager has more information about the way how those events affect the effectiveness of abatement effort. We also implicitly assume that the existence of specific knowledge makes it very costly for the manager to communicate this information to the firm. In this sense, our paper is related to Raith (2008) in several aspects: limited liability, input and output performance measures etc. However, in his paper effort is contractible and there are only imperfect output measures, while in our model effort is only ex-ante contractible and output is verifiable. Besides, we do not allow for contracts on both measures (effort and abatement) simultaneously.
} 
The private first-best $(P F B)$ corresponds to a situation without informational asymmetries (or equivalently, a joint optimization problem). The minimization of total costs, given by taxes and the cost of effort, $t P+c(e)$, gives as a result $e^{P F B}=\frac{t x}{c}$.

The abatement activities can be organized according to an informal (I) or a standardized $(S)$ EMS. We say that the firm "adopts $I$ or $S$ ". We also consider the possibility that no EMS is adopted, which means that no manager is contracted and no effort is made $(e=0)$. We label this case as "laissez-faire" (LF). Formally, we represent the adoption decision by a qualitative variable $E M S$ that can take three values: $S, I$ and $L F$.

\subsection{Informal $(I)$ and Standardized $(S)$ EMS}

The main feature of an informal EMS that we want to underline is that it is not restricted to follow a rigid protocol and, hence, it provides more flexibility at the cost of reducing the level of internal control. This idea is captured by assuming that, under $I$, the firm lets the manager decide the level of effort, which is not observable by the firm. The firm must provide a contract based on verifiable results and the natural candidate is the amount of abatement $(A-P)$ or, equivalently, the level of emissions $(P)$. We assume a linear contract $w_{I}=a+b(A-P)=a+b(e x), a$ being the basic salary and $b$ a bonus per unit of emissions reduced.

Under $I$ the timing of the game is such that the firm offers a salary scheme to the manager before uncertainty is revealed. If he accepts, the value of $x$ is revealed only to him and he decides the level of effort. This effort, together with the realization of the shock, determines emissions and, hence, the manager's salary and the tax bill. We use the equilibrium concept of perfect sub-game. In the final stage of the game, the manager decides $e$ to maximize his utility after observing $x$, resulting in the following Incentive 
Compatibility Constraint (ICC):

$$
e_{I}=\frac{b x}{c} .
$$

As a second option, a standardized EMS involves a protocol that provides the firm with a better control. We model this fact by assuming that effort becomes verifiable and can be specified in the contract. On the other hand, the obligation to follow a rigid protocol makes the firm less reactive to changes in the environment because any adaptation of the system requires a bureaucratic procedure. We capture this idea in a simplified way by assuming that the firm must decide the level of effort (and include it in the contract) before the uncertainty is revealed and such level cannot be modified afterwards. Since $x$ is revealed only after signing the contract, the firm is not able to identify the optimal level of effort. ${ }^{7}$ Summing up, $S$ provides more control and avoids incentive rents, but it is more rigid since effort cannot be adjusted to different values of the shock. ${ }^{8}$ Under $S$ the firm offers a contract to the manager (including $w$ and $e$ ) before uncertainty is resolved and the manager exerts the level of effort specified in the contract whatever the realization of the shock.

\section{Optimal Contracts and the Adoption Decision}

Consider, first, that the firm adopts $I$. The firm designs the contract that minimizes her expected costs taking into account (PC), (LLC) and (ICC). The solution to this problem

\footnotetext{
${ }^{7}$ We are implicitly assuming a particular monitoring technology that allows a certain control over manager's actions. Other technologies may allow to infer some information about the real state of the world (see, for instance, Baker 1992). This simple technology allows us to highlight the loss of flexibility caused by adopting $S$ rather than $I$.

${ }^{8}$ Although $S$ is more rigid than $I$, it is more flexible than a command-and-control policy. In our setting, a natural way to model a command-and-control policy would be to set a legally required level of effort. Although, under $S$, the firm commits to a fixed level of effort, such level is endogenously decided by the firm, not legally set by the government.
} 
is given in Lemma 1.

Lemma 1 Adopting I is more profitable for the firm than the laissez-faire (LF) situation if and only if $t>\underline{t}_{I}$, where $\underline{t}_{I} \equiv \sqrt{\frac{2 c \underline{U}}{\left(\sigma^{2}+\mu^{2}\right)}}$. Moreover, under $I$,

(a) If $\underline{t}_{I}<t<2 \underline{t}_{I}$, the optimal payment scheme is given by $(a, b)=\left(0, \underline{t}_{I}\right)$, contingent effort is $e_{I}=\frac{x \underline{t}_{I}}{c}$, the firm's expected costs are $E C_{I}=t\left(A-\sqrt{\frac{2\left(\sigma^{2}+\mu^{2}\right) \underline{U}}{c}}\right)+2 \underline{U}$ and the expected utility of the manager is $E u=\underline{U}$.

(b) If $t>2 \underline{t}_{I},(a, b)=\left(0, \frac{t}{2}\right), e_{I}=\frac{t x}{2 c}$ and $E C_{I}=t A-\frac{t^{2}\left(\sigma^{2}+\mu^{2}\right)}{4 c}$. In this region, the manager obtains positive incentive rents, i.e., $E u>\underline{U}$.

(c) If $t=2 \underline{t}_{I}$ the firm is indifferent between both schemes

Lemma 1 reveals that the firm trades off the cost of hiring the manager and the cost of paying taxes. When $t<\underline{t}_{I}$, emissions charges are very low with respect to $\underline{U}$ and contracting the manager is too costly compared to the tax saving that the firm could make by contracting him. Therefore, it is optimal not to hire the manager and not to abate at all $\left(e_{I}=0\right)$. Then, emissions are equal to $A$ and the tax bill is $t A$.

For intermediate values of $t\left(\underline{t}_{I}<t<2 \underline{t}_{I}\right)$, the tax burden becomes an issue for the firm and implementing some $E M S$ is preferable to LF. But contracting the manager is still very costly in relative terms and the firm prefers to offer a contract just good enough to make the manager accept it, by setting a constant bonus. Such a payment scheme is enough to encourage the manager to exert a "low" level of effort (technically, that level just compatible with the LLC) since incentivizing a higher level would entail accepting that the manager earns some incentive rents, and the cost of those rents would not be compensated by the achieved saving on taxes. Thus, in this range, the average level of effort is "low" and independent of $t$, while emissions are constant on $t$ but lower than $A$. 
Finally, when the tax rate is high enough $\left(t>2 \underline{t}_{I}\right)$, saving on taxes becomes relevant enough to compensate for the provision of incentive rents and it is optimal to offer an adaptive bonus, which is increasing with $t$. The optimal level of effort is increasing and the resulting level of emissions is decreasing in $t$. Nevertheless, even in the upper range, the presence of incentive rents causes that the optimal bonus is $b=\frac{t}{2}$, rather than $b=t$, what would be required to implement the first best, i.e., the firm chooses not to fully transfer the tax incentive to the manager.

The fact that $a=0$ in both cases means that the firm uses the variable bonus $b$ and not the basic salary $a$ to satisfy the PC, which is binding in both cases (a) and (b). The reason why $a>0$ is not optimal in this setting is that the firm could increase its profit by reducing the basic salary and increasing the bonus, while maintaining constant the expected salary of the manager but inducing a higher level of effort (whatever $x$ ). So, one source of inefficiency in this context lies in the dual role of the bonus, on the one hand, to give incentives to the manager in order to choose the right level effort and, on the other hand, to make him accept the contract.

Assume now that the firm adopts $S$, so effort can be prescribed in the contract. There is no need for incentives and it suffices to offer a constant basic salary to make the manager willing to accept. The properties of such a contract are shown in Lemma 2.

Lemma 2 Adopting $S$ is more profitable for the firm than $L F$ if and only if $t>\underline{t}_{S}$, where $\underline{t}_{S} \equiv \frac{\sqrt{2 c \underline{\underline{U}}}}{\mu}$. Moreover, when the firm adopts $S$,

(a) the effort imposed to the manager is given by $e_{S}=\frac{t \mu}{c}$, the salary is $w_{S}=\underline{U}+\frac{t^{2} \mu^{2}}{2 c}$ and the manager's expected utility is always $\underline{U}$.

(b) The firm's expected cost is given by $E C_{S}(t)=t A-t^{2} \frac{\mu^{2}}{2 c}+\underline{U}$ 
Since the firm does not observe $x$, the best she can do is to use its unconditional mean. Note that $e_{S}$ is equal to $e^{P F B}$ only if the true realization of $x$ is equal to $\mu$. The closer $x$ is to $\mu$, the more efficient this system is. Conversely, $S$ can perform very poorly when $x$ is very different from $\mu$.

Adopting $S$ is profitable for the firm only if $t$ is high enough, what entails a minimum level of effort, associated to $t=\underline{t}_{S}$ and given by $\underline{e}_{S} \equiv \sqrt{\frac{2 \underline{U}}{c}}$. Using $\underline{t}_{S}$ and $\underline{e}_{S}$, the minimum cost of implementing $S$ is $\underline{w}_{S}=2 \underline{U}$, which can be seen as a set-up cost, with the particular feature that it is not an exogenous amount, but an endogenously determined cost. Note also $\underline{t}_{S}>\underline{t}_{I}$, i.e., a higher tax is needed to induce firms to adopt $S$ than to adopt $I$, i.e., $S$ entails a higher set-up cost than $I$.

Another difference between the solutions under $I$ and $S$ is that the former depends on the variance of $x$ while the latter does not. The firm, being risk neutral, is not concerned by the variance itself. Under $I$, the firm does care about the variance only because of the complementarity of effort and the realization of the random shock $x$ (according to (ICC)). This effect is not present under $S$ since effort is chosen before uncertainty is revealed.

Proposition 1 Given any $t \geq \underline{t}_{S}$, the (certain) level of effort chosen by a firm under $S$ is not lower than the expected level of effort under $I$. Formally $e_{S}(t) \geq E e_{I}(t)$. Moreover, for a given $t$, expected emissions under $S$ are lower than under $I$ (formally $E P_{S}<E P_{I}$ ) if and only if both of the following conditions hold:
a) $\rho<1$,
b) $t>t^{e}$, where $t^{e} \equiv \underline{t}_{S} \sqrt{1+\rho^{2}}>\underline{t}_{S}$

Proposition 1 states that, under any tax ( $t$ being high enough to discard LF) those firms adopting $S$ exert, on average, more effort than those adopting $I$. This result is 
consistent with the common belief (also supported by the empirical evidence) that firms with a standardized EMS tend to be greener. Yet, it is important to make some important remarks about this claim. First, effort is certain ex-ante under $S$ whereas it is unknown under $I$. This implies that, at the individual level, although $S$-adopting firms exert more effort on average, this is not necessarily true for two arbitrary firms. If $x$ is high enough, a firm under $I$ could make more effort than another firm under $S$. At the more aggregate level, notice that, depending on the distribution of $x, e_{S}(t) \geq E e_{I}(t)$ does not necessarily imply that a majority of firms adopting $I$ exert less effort that $S$-adopting firms. A sufficient condition for this result would be that the distribution of $x$ is symmetric. Our second remark is that a firm might adopt $S$ not (only) due to greenness, but (also) to a cost saving motive

And third, although those firms adopting $S$ tend to spend more resources on abatement, it might be the case that they pollute more than firms adopting $I$. This counterintuitive result is due to the rigidity introduced by $S$ and the complementarity between $e$ and $x$. The impossibility to react to different values of $x$ might generate a loss of efficiency. This lack of flexibility is more serious when $x$ is very volatile. Actually, if $\rho \geq 1$ firms tend to pollute more under $S$ than under $I$. Requirement $b$ ) in Proposition 1 reinforces the set-up cost idea introduced above: for $S$ to be more profitable than LF, taxes need to be "high enough" $\left(t>\underline{t}_{S}\right)$, but they need to be even higher $\left(t>t^{e}\right)$ for $S$ to generate more abatement than $I$. This result suggest a complementarity between $S$ adoption and public policies in the sense that a standardized EMS might be not enough to reduce pollution if it is not complemented by adequate public incentives.

We study now the adoption decision. If $t<\underline{t}_{I}$, from lemmas 1 and 2 we know that LF is trivially more profitable than $S$ or $I$. Proposition 2 refers to the non-trivial cases. 
Proposition 2 Assume $t \geq \underline{t}_{I}$. If $\rho \geq 1$ it is never optimal for the firm to adopt $S$. If $\rho<1$ there is a threshold level for the tax rate, $t^{*}$, such that it is optimal to implement $S$ (rather than I) if and only if $t \geq t^{*}$ (with indifference at $t=t^{*}$ ) where $t^{*}$ is defined as

$$
t^{*} \equiv \begin{cases}\frac{\sqrt{2 c \underline{U}}}{\mu}\left[\rho+\sqrt{\rho^{2}+1}\right] & \text { if } \rho \in\left(0, \frac{\sqrt{3}}{3}\right) \\ \frac{2}{\mu} \sqrt{\frac{c \underline{U}}{\left(1-\rho^{2}\right)}} & \text { if } \rho \in\left[\frac{\sqrt{3}}{3}, 1\right)\end{cases}
$$

According to Proposition 2, adoption depends on two elements. First, the relative volatility of $x$. When uncertainty is low, adopting $S$ allows the firm to select a level of effort that, with a high probability, is very close to the first best. So, the loss of flexibility is not a big problem. If, on the contrary, volatility is high, an informal EMS is more advisable because flexibility is very important to be able to react to different values of the shock. A low value of $\rho$ can be interpreted as a framework (say, an activity sector) in which the abatement technology is well established whereas a high value of $\rho$ might indicate that the technology is at an early stage of development and subject to larger uncertainty. Another plausible interpretation is that standardized systems are more prone to be adopted by well established and mature firms (typically facing lower uncertainty) rather than by newcomer firms.

The second factor is the tax, what reinforces the idea of complementarity between $S$ adoption and public incentives. For every value of $\rho$ there is a threshold value of $t$ over which $S$ is adopted. ${ }^{9}$ The rationale behind this finding lies in the fact that, under $I$, the firm has to balance the objectives of reducing the tax burden and keeping the manager's wage low. The presence of incentive rents raises the cost of giving incentives, what dampens the reaction of the firm to a higher tax rate. This effect is not present under $S$ since effort is

\footnotetext{
${ }^{9}$ Notice that $t^{*}$ is continuous since both expressions in Proposition 2 take the same value at $\rho=\frac{\sqrt{3}}{3}$.
} 
observable and there are no incentive rents. Thus, the firm is, on average, more responsive to changes in tax rate under $S$ than under $I$. This finding reinforces the first result in Proposition 1 in the following sense: for the same $t$, firms adopting $S$ exert, on average, more effort. Moreover, $S$ tend to be adopted when emissions charges are high, which gives an additional factor to justify why $S$-adopting firms make more effort: it is likely that those firms adopting $S$ are subject to higher taxes (or, in general, are more exposed to cost derived from pollution). Figure 1 illustrates this result.

Corollary 1 If it is optimal for the firm to adopt $S$, the expected emissions under $S$ are not higher than the expected emissions under $I$. Formally, $t \geq t^{*} \Longrightarrow E P_{S}(t) \leq E P_{I}(t)$

Corollary 1 states that, although firms adopting $S$ might pollute, on average, more than firms adopting $I$ (see Proposition 1), it is not expected that cost-minimizing firms would endogenously adopt $S$ in those circumstances.

\section{Social costs and optimal policy}

So far we have taken public policy as given and we have focused on the firm's decision. In this section we analyze how the environmental authority should set taxes to minimize social cost. Modifying $t$ has two differentiated effects. First, a marginal effect in the sense that an increase in $t$ will typically lead firms to increase abatement effort. Second, a qualitative or discrete effect since changing $t$ might imply a change in the firm's adoption strategy, i.e. shifting from $I$ to $S$ or vice versa. We conclude that the combination of these effects might result in a conflict between private and social interests, in the sense that the social optimum could not be implemented because it requires the adoption of a particular EMS whereas the firm is willing to adopt a different one. This conflict is driven by the fact 
that the firm's and the planner's preferences are different. The firm is concerned about the existence of incentive rents, which represent a source of costs for her, whereas these rents are, per se, not a relevant problem for a social planner since they can be seen as an income transfer (from the firm to the manager) and, therefore, the aggregate social effect is zero. On the other hand, the planner is concerned about the social damage caused by emissions, while the firm is not. We split the optimal policy problem in two stages: determining the social optima and investigating the possibility to implement them.

\subsection{Determining the social optima}

We assume that the social planner aims at minimizing expected social costs associated to emissions, which are given by the abatement cost and the external cost of pollution, $D(P)$. Using (2) total social cost is given by ${ }^{10}$

$$
S C=\frac{c}{2} e^{2}+\frac{\delta}{2} P^{2}
$$

The planner needs to take into account the firm's decision to adopt $S$ or $I$. First we study the optimal value of $t$ under both scenarios and then we determine which one is socially preferable. To this end, it is useful to introduce a couple of definitions.

Definition 1 A policy, $P(E M S, t)$, is a type of $E M S \in\{I, S, L F\}$ and a tax rate, $t$.

\footnotetext{
${ }^{10}$ Tax revenue and the manager's salary are not considered as costs, but income transfers, from the social point of view. As noted by one referee, it can be argued that the manager's reservation utility, $\underline{U}$, should be included with a negative sign under $L F$ or, alternatively, with a positive sign under $S$ and $I$, to acknowledge the social opportunity cost to divert the manager from another activity. We do not do so for two reasons. The first is analytical clarity and the second is to assume that the planner only considers those agents that are effectively involved in the sector and not those that could have been potentially involved but ultimately are not. This is based on the idea that a proper evaluation of the social opportunity cost would require more information. For example, in the presence of involuntary unemployment, contracting the manager creates a new job, which could (totally or partially) counterbalance the opportunity cost. Our setting can be seen as a worst-case scenario for LF. Including $\underline{U}$ would make $L F$ to be socially optimal more often.
} 
Denote as $P^{L F}$ any policy involving $E M S=L F .^{11}$

Under LF, we have $e=0$ and $P=A$. In this case social cost is certain and given by $S C_{L F}=\frac{\delta}{2} A^{2}$ for any $t$. Under $S$ or $I$ the tax rate matters for social cost because it determines the level of effort and emissions. So, we wonder what is the socially optimal value of $t$ under each EMS, what corresponds to the notion of Pigouvian tax.

Definition 2 The "standardized local optimum" or "S-optimum" is a policy defined by $P\left(S, t^{S}\right)$, where $t^{S}$, is the tax rate that minimizes $E S C$ under $E M S=S$. Analogously, the "informal local optimum" or simply "I-optimum" is $P\left(I, t^{I}\right)$, where $t^{I}$ is the tax rate that minimizes expected social cost subject to $E M S=I$.

Assume first $E M S=S$. Using (1) and taking expectations in (4), together with the fact that under $S$ effort is observable, we get the following expression for the expected social cost:

$$
E S C_{S}=\frac{c}{2} e^{2}+\frac{\delta}{2}\left[(A-e \mu)^{2}+\sigma^{2} e^{2}\right]
$$

Using the expression for $e_{S}$ given in Lemma 2 we can write $E S C_{S}$ in terms of the tax, and minimizing this function with respect to t, we get the following form for the (Pigouvian) socially optimal tax under $S$ :

$$
t^{S}= \begin{cases}\underline{t}_{S} & \text { if } \underline{A}_{S} \leq A<2 \underline{A}_{S} \\ \frac{A c \delta}{\delta\left(\mu^{2}+\sigma^{2}\right)+c} & \text { if } A>2 \underline{A}_{S}\end{cases}
$$

where $\underline{A}_{S} \equiv \frac{c+\delta\left(\mu^{2}+\sigma^{2}\right)}{\delta \mu} \sqrt{\frac{\underline{\underline{U}}}{2 c}}$ is a threshold value of $A$ below which $S$ is never socially optimal. The first region defined in (6) is a corner solution and the second is interior. The first region

\footnotetext{
${ }^{11}$ Since social cost does not directly depend on taxes, under $\mathcal{P}^{L F}$ the exact value of $t$ is socially irrelevant as far as it is low enough to induce firms not to adopt any EMS.
} 
reveals that, when $A$ is not very high, the optimal policy is to set a tax that is just high enough to induce the firm to adopt $S$. Straightforward sensitivity analysis for the second region reveals that, as expected, $t^{S}$ is higher for big or highly polluting firms (higher $A$ ), when pollution is more harmful (higher $\delta$ ), when effort is more costly (higher $c$ ) and effort is, on average, less productive (lower $\mu$ ). It is interesting to underline that $t^{S}$ also depends negatively on $\sigma^{2}$ because, although the private solution of the firm under $S$ does not depend on the variance (see Lemma 2), the social cost does according to (5). To understand the effect of $\sigma^{2}$, it is useful to interpret abatement effort as an investment. Since the damage function is quadratic, the social planner prefers certain to uncertain outcomes. When $\sigma^{2}$ is high, the effectiveness of abatement effort is very uncertain, what makes it be less appealing as an investment and, therefore, less incentives (=taxes) are advisable.

Under $I$, using Lemma 1 in (4) and taking expectations we get an expression for $E S C_{I}$ in terms of the tax, and minimizing with respect to $t$, we get the $I$-optimum tax rate:

$$
t^{I}= \begin{cases}\text { any } t \in\left[\underline{t}_{I}, 2 \underline{t}_{I}\right] & \text { if } \underline{A}_{I} \leq A<2 \underline{A}_{I} \\ \frac{2 A c \delta}{\delta \frac{\gamma}{\left(\mu^{2}+\sigma^{2}\right)}+c} & \text { if } A>2 \underline{A}_{I}\end{cases}
$$

where $\underline{A}_{I} \equiv \frac{c+\delta \frac{\gamma}{\mu^{2}+\sigma^{2}}}{\delta} \sqrt{\frac{\underline{U}}{2 c\left(\mu^{2}+\sigma^{2}\right)}}$ is a threshold value below which $I$ is never socially optimal and $\gamma \equiv \int x^{4} d F(x)$ is the fourth-order non-centered moment of $x$. The first range of $t^{I}$ corresponds to the first region of the firms' optimal solution, when the contract and the effort do not depend on the tax (see point (a) in Lemma 1). In the second range, the effect of $A, c$ and $\delta$ have the same sign as they had on $t^{S}$. Nevertheless, the distribution of $x$ affects $t^{I}$ in a different way. First, note that $\mu^{2}$ and $\sigma^{2}$ have a positive rather than negative effect. The reason is that, unlike under $S$, the manager reacts to different values 
of the random shock and this adaptive capacity is more important the bigger the size of the shock and its variability. However, since the tax incentive is not fully transferred to the manager, the more uncertain the shock is, the more advisable it is to increase the tax to reinforce the incentive that the manager will ultimately receive. On the other hand, there is now an additional term, $\gamma$, which is related to the kurtosis coefficient. ${ }^{12}$ For symmetric distributions, the higher $\gamma$ (and, hence, the kurtosis coefficient) the more mass of probability is located closely around the mean and in the tails, what induces the regulator to fix a lower tax, resulting in lower effort. The reason for this effect is the fact that $e_{I}$ increases linearly with $x$, whereas the social-first-best (SFB) level of effort is decreasing for large values of $x .^{13}$ So, if $x$ is very high, the approximation of $I$ to the social optimum can be very poor (the firm tends to over-abate), and this event is more probable the more mass is located in the tails.

Both the $S$-optimum and the $I$-optimum can be seen as local optima in the sense that $t^{S}$ is optimal under $S$ but, in general, it is not optimal under $I$, and the same applies to $t^{I}$. The third local optimum is $P^{L F}$. We refer to the local optimum with the smallest $E S C$ as the global optimum or $G$-optimum. So, the $G$-optimum, is $P\left(S, t^{S}\right)$ if $E_{S} S C\left(t^{S}\right) \leq$ $\min \left\{S C_{L F}, E_{I} S C\left(t^{I}\right)\right\}$ and so on.

It is easy to check that $L F$ is the $G$-optimum if $A$ is small enough; specifically, if $A \leq \underline{A}^{G} \equiv \min \left\{\underline{A}_{I}, \underline{A}_{S}\right\} .{ }^{14}$ The intuition behind this result is straightforward: if $A$ is

\footnotetext{
${ }^{12}$ The kurtosis coefficient, defined as $\frac{\int(x-\mu)^{4} d F(x)}{\sigma^{4}}$, measures the fourth-order centered moment with respect to the second-order centered moment. Ceteris paribus (taking as fixed the $1^{\text {st }}, 2^{\text {nd }}$ and $3^{\text {rd }}$-order moments) the kurtosis coefficient is increasing with $\gamma$. A high-kurtosis distribution has a sharper peak and longer, fatter tails, while a low kurtosis distribution has a more rounded peak and shorter thinner tails.

${ }^{13}$ Specifically, by minimizing $S C$, we get the social first-best (SFB), $e^{S F B}=\frac{A \delta x}{c+\delta x^{2}}$, which depends positively on $x$ for low values of $x$ and negatively for large values, since the positive marginal contribution of $e$ to social cost is increasing whereas its negative marginal contribution (through abatement) is decreasing. A linear contract is not able to deal optimally with this non-linear shape.

${ }^{14}$ We get $\underline{A}_{G}=\underline{A}_{I}$ if $W \leq \sqrt{\left(1+\rho^{2}\right)}$ and $\underline{A}_{G}=\underline{A}_{S}$ if $W \geq \sqrt{\left(1+\rho^{2}\right)}$.
} 
small, the impact of pollution is not very important and reducing is not worth the cost of implementing an EMS. Proposition 3 states under which conditions $\mathcal{P}\left(S, t^{S}\right)$ is socially preferred to $\mathcal{P}\left(I, t^{I}\right)$ and vice versa when $A$ is big enough to discard LF. The results are mainly governed by the weighted preference ratio (WPR) defined as

$$
W \equiv \frac{\frac{\delta}{c}\left(\frac{\gamma}{\sigma^{2}+\mu^{2}}\right)+1}{\frac{\delta}{c}\left(\sigma^{2}+\mu^{2}\right)+1} .
$$

Proposition 3 If $A \geq \underline{A}^{G}$ the G-optimum is determined by the following results:

1. If $W \leq \sqrt{1+\rho^{2}}$, the G-optimum is $\mathcal{P}\left(I, t^{I}\right)$.

2. If $\sqrt{1+\rho^{2}} \leq W \leq 1+\rho^{2}$, there exists $\hat{A}$ such that the $G$-optimum is $\mathcal{P}\left(S, t^{S}\right)$ if $A \leq \hat{A}$ and $\mathcal{P}\left(I, t^{I}\right)$ if $A \geq \hat{A}$.

3. If $W \geq 1+\rho^{2}$, the $G$-optimum is $\mathcal{P}\left(S, t^{S}\right)$.

With indifference when the inequalities hold with "="

Figure 2 shows that the range where the $G$-optimum is $P\left(S, t^{S}\right)$ widens with $W$ and so this ratio determines to what extent $S$ is preferred to $I$. $W$ combines two elements. The first trades-off social and private concerns by means of the ratio $\frac{\delta}{c}$ (importance of emissions vs. the cost of effort). If $\frac{\delta}{c}$ is high, $S$ tends to be preferred to $I$ since it tends to generate more abatement effort. ${ }^{15}$

The second factor is the distribution of $x$. Higher variance makes $S$ less appealing since, being more rigid, it makes it more difficult to react to a changing environment. The $4^{\text {th }}$-order moment $\gamma$ favors $S$ as more probability mass is located closely around the mean and in the tails. With more mass around the mean, $x$ is more likely to be close to its mean,

\footnotetext{
${ }^{15}$ This can be checked by inspecting Proposition 1 and Corollary 1. Additionally, it can be proved that, the abatement effort in the $S$-optimum is not lower than the expected effort in the $I$-optimum, i.e., $e_{S}\left(t^{S}\right) \geq E e_{I}\left(t^{I}\right)$, i.e., it is not only the case that those firms adopting $S$ privately tend to exert more abatement effort, but it is also socially optimal that they do so.
} 
which makes $S$ more efficient. More mass in the tails also favors $S$ because, as we have discussed above, under $I$ the firm tends to over-abate in the higher tail.

\subsection{Conflicts between social and private plans and optimal poli- cies}

In this Section we explore under which conditions firms' interests conflict with those of the regulator in the sense that some socially optimal policies cannot be implemented. To this end, we introduce the concept of implementable policy.

Definition 3 A policy $\mathcal{P}\left(E M S_{0}, t_{0}\right)$ is said to be implementable if, given the tax rate $t_{0}$, it is optimal for the firm to adopt $E M S_{0}$, where $E M S_{0} \in\{I, S, L F\}$.

As an example, consider the situation depicted in Figure 3. The $G$-optimum is $P\left(S, t^{S}\right)$ but it cannot be implemented since, under $t=t^{S}$, the firm will adopt $I$ rather than $S$. Then, under $t^{S}$ actual social cost would be $E S C_{I}\left(t^{S}\right)$, well above $E S C_{S}\left(t^{S}\right)$. Anticipating this undesired event, the regulator can "distort" the tax. By "distorting" we mean to select a $t$ different from the $G$-optimum value, with the aim to induce the firm to make an adoption decision more compatible with social interests. In our example, by setting $t=t^{*}$, it is possible to induce the firm to adopt $S,{ }^{16}$ with a social cost equal to $E S C_{S}\left(t^{*}\right)$, which is above the global minimum value, but below $E S C_{I}\left(t^{S}\right)$, what would prevail under $t^{S}$.

An obvious case of disagreement happens when the $G$-optimum is $P\left(S, t^{S}\right)$ and $\rho \geq 1$. In this case, the firm never adopts $S$ (see Proposition 2). Then, the regulator's options would be $P^{L F}$ and $P\left(I, t^{I}\right)$. For simplicity, we rule out this case by introducing the following technical assumption:

\footnotetext{
${ }^{16} \mathrm{At} t^{*}$ the firm would be indifferent between $S$ and $I$. We arbitrarily assume that firms are naive in the sense that, when they are indifferent, they choose the system that the regulator prefers.
} 
Assumption 1: $\rho \in\left(\frac{\sqrt{3}}{3}, 1\right)$.

This is a two-fold assumption since it eliminates two cases. First, it rules out $\rho \geq 1$. The reason to disregard this case is that when $\rho \geq 1$ firms will never adopt $S$, what makes $P\left(S, t^{S}\right)$ irrelevant (see Proposition 2). Second, Assumption 1 implies $\rho>\frac{\sqrt{3}}{3}$, what restricts our discussion to the region in which, under $I$, there are incentive rents, which is one of the key elements of our discussion. The $\rho \leq \frac{\sqrt{3}}{3}$ case can be studied in a similar way, but it provides no additional insights and it makes the calculus more cumbersome.

Clearly, $L F$ can be implemented if $t$ is low enough (specifically, $t<\underline{t}_{I}$ ). Implementing the $S$-optimum requires $t^{*} \leq t^{S}$ since, otherwise, the firm would choose $I$ when facing $t^{S}$. Symmetrically, $\mathcal{P}\left(I, t^{I}\right)$ requires $t^{*} \geq t^{I}$ since, otherwise, the firm would adopt $S$ when facing $t^{I}$. Lemma 3 states the implementability of the local optima in terms of the tax thresholds and in terms of the BAU emissions.

Lemma $3 \mathcal{P}\left(S, t^{S}\right)$ is implementable if and only if $t^{S} \geq t^{*}$ and $\mathcal{P}\left(I, t^{I}\right)$ is implementable if and only if $t^{*} \geq t^{I} \geq \underline{t}_{I}$. Moreover, there exist two thresholds, $A^{S}, A^{I}$, such that $\mathcal{P}\left(S, t^{S}\right)$ is implementable if and only if $A \geq A^{S}$ and $\mathcal{P}\left(I, t^{I}\right)$ is implementable if and only if $\underline{A}_{I} \leq A \leq A^{I}$

According to Lemma $3 P\left(S, t^{S}\right)$ is implementable when $A$ is high enough, whereas $P\left(I, t^{I}\right)$ requires that $A$ is not too high (it cannot be too low either, in order to avoid $L F)$. Therefore, under optimal taxation, highly polluting firms tends to adopt $S$ since a higher $A$ makes it more probable that $t^{S}>t^{*}$ holds, and therefore, the $S$-optimum is implementable. But if $A$ is high, it is also more likely that $t^{*}<t^{I}$ holds, what implies that the $I$-optimum is not implementable. So, the larger $A$, the more likely it is that there is a conflict in the direction that the social planner prefers $I$ and the firm prefers $S$. We 
say that there is overadoption when the firm tends to adopt $S$ more often than it is socially desirable. As a policy conclusion, Lemma 3 states that overadoption tends to appear when BAU emissions are high.

Conversely, $I$ is more attractive for firms with low $A$. The lower $A$, the more likely $t^{*}>t^{I}$ will hold $\left(\mathcal{P}\left(I, t^{I}\right)\right.$ is implementable) but also $t^{S}<t^{*}\left(\mathcal{P}\left(S, t^{S}\right)\right.$ is not $)$. Then, the smaller $A$, the more likely is the event of underadoption in the sense that the firm tends to adopt $S$ less often than it is socially desirable. Table 1 and Figure 4 illustrate the implications of Proposition 3 and Lemma 3.

Table 1. Conflicts between private and social plans

Figure 4 reveals that, when $A$ is very low, the pollution problem is not very severe and both the firm and the planner prefer LF. This situation is represented in the white area labelled as "no conflict $L F$ ", where "no conflict" means that the $G$-optimum is implementable. When both $A$ and the WPR are large, public and private preferences are aligned towards $S$ ("no conflict $S$ "). The fact that $S$ entails a higher set-up cost (see Section 3 ) causes that large and heavily polluting firms are more prone to adopt it, while a higher value of the WPR also implies a stronger social preference towards $S$ (see Proposition 3 ). Similarly, for low values of $W$ and intermediate values of $A$, the regulator and the firm concur on $I$ ("no conflict $I$ "). For other combinations, conflicts between public and private interests arise, resulting in over and underadoption (striped areas in the figure). 
The problem faced by the government is to find the best policy that is compatible with the firm's decision. Label the solution to this problem as implementable (or feasible) optimum, or simply $F$-optimum, as introduced in the following definition.

Definition 4 The feasible optimum, or F-optimum, is a policy, say $P(\widehat{E M S}, \hat{t})$, that minimizes the expected social cost subject to the constraint that $P(\widehat{E M S}, \hat{t})$ is implementable.

When $A$ is small enough, specifically $A<\underline{A}^{F} \equiv \min \left\{\underline{A}_{I}, A^{S} / 2\right\}$, the $F$-optimum involves LF since LF it is the $G$-optimum and it is implementable. Otherwise (i.e. $A \geq \underline{A}^{F}$ ), it can be proved (see Lemma 4, in Appendix 2) that $\hat{t}$ can only be either $t^{S}, t^{I}$ or $t^{*}$.

Appendix 1 provides a complete formal characterization of the $F$-optimal policies depending on BAU emissions and the WPR. To get an intuitive idea of how the F-optimum looks like (and hence how the regulator should deal with conflicts) we use an example that is shown in Figure 5. The $G$-optimum areas (delimited by dotted lines) are superposed with the $F$-optimum areas.

Consistently with the classification shown in Table 1, there are three non-conflict regions where the $G$-optimum is implementable, labelled respectively as "No conflict (S)", "No conflict (I)" and "No conflict (LF)". In these cases, the optimal decision of the planner is to implement the $G$-optimum. The cases of conflict can be dealt with in two different ways. The general idea is that the planner should incentivize the firm to implement the (socially) "right" type of EMS if this can be done with a "moderate" tax distortion and should accept that the implemented EMS is different from the $G$-optimum otherwise. To get a better understanding of the specific meaning of "moderate" in this framework, we discuss now the shape of the relevant areas with the help of Figure 5. 
Notice first that LF happens more often in the $F$-optimum than in the $G$-optimum. Indeed, between $\underline{A}^{G}$ and $\underline{A}^{F}$ the global optimum $P\left(S, t^{S}\right)$ it is not implementable and any attempt to implement an EMS (either $S$ or $I$ ) would require a strong tax distortion that would be socially worse than LF. This area is labelled as " $S$ to $L F$ " to indicate that the $G$-optimum involves $S$ whereas the $F$-optimum involves $L F$. The main message in this area is that, $A$ being small, the social relevance of emissions is limited and, therefore, it is better to accept the $L F$ level rather than the inefficiency costs associated to the tax distortion. Let us focus now on the regions where LF is not $F$-optimal.

Consider now the region where the $G$-optimum involves $I$. If $A$ is low enough, $P\left(I, t^{I}\right)$ is implementable and there is no conflict. If, on the contrary, $A$ is high, overadoption arises. How the planner deals with this event depends on $A$. If $A$ is close enough to $A^{I}{ }^{17}$ it is profitable for the planner to apply a moderate tax distortion in order to induce the firm to adopt $I$. The resulting policy is $P\left(I, t^{*}\right)$ (area labelled "Tax distortion $(I)$ " in Figure 5). ${ }^{18}$ If $A$ is very large the $F$-optimal policy involves $S$ (area labelled as " $I$ to $S$ "), which means that the government renounces to get $I$ implemented because inducing firms to do so would require a strong tax distortion.

When the $G$-optimum involves $S$, it is implementable (no conflict) only if $A$ is large enough. Otherwise, there is underadoption. The policy options to deal with this conflict are determined by the weighted preference ratio. If $W$ is large enough ${ }^{19}$ the social preference towards $S$ is so strong that $I$ must be ruled out and the tax is always distorted (to

\footnotetext{
${ }^{17}$ In Appendix 1 we give a precise specification for "close enough". Specifically, we show that there exists one threshold $A^{*}$ such that, if $A^{I}<A \leq A^{*}$, it is better to distort the tax and force the firm to implement $I$ and, if $A \leq A^{*}$, the planner should opt to accept $S$ instead of $I$.

${ }^{18}$ By a "moderate tax distortion" we mean that $t^{*}$ is not very far from the $G$-optimum value, since by construction, when $A=A^{I}, t^{I}=t^{*}$ and, by continuity, if $A$ is close to $A^{I}, t^{*}$ is close to $t^{I}$. If $A$ is above $A^{*}$, we say that there is a "strong" tax distortion in the sense that $t^{*}$ would be very far from $t^{I}$.

${ }^{19}$ In Proposition 4 (Appendix 1) we define a threshold $\bar{W}$, which determines the meaning of "large enough" in this case.
} 
$\left.t^{*}\right)$ to make sure than the firm chooses $S$. It also pays to distort the tax for intermediate values of the WPR if $A$ is high enough. ${ }^{20}$ Even if $S$ is globally optimal, when the social preference towards $S$ (as measured by $W$ ) is moderate and $A$ is not very large it is more preferable to induce $I$ because encouraging firms to adopt $S$ would entail a sharp distortion (this corresponds to the " $S$ to $I "$ region).

\subsection{Win-win-win introduction of Standardized EMS}

Assume that the planner always aims to set the F-optimum. Consider that, starting from a situation where only the LF and informal EMS exist, the possibility to adopt a standardized EMS is introduced. Corollary 2 identifies a case in which this introduction results in a win-win-win situation in the sense that it is simultaneously profitable for the firm, the society and the environment. Moreover these improvements are consistent with a tax reduction.

Corollary 2 Consider an initial situation in which $S$ is not available. If $W \in\left(1+\rho^{2}, 2\right)$ there exists a threshold $A^{L} \in\left(A^{I}, A^{S}\right)$ such that, if $A>A^{L}$ the introduction of $S$ entails an improvement from the point of view of the firm (lower expected private cost), the society (lower expected social cost) and the environment (lower expected emissions). This comes along with a reduction of the tax rate

When $S$ is not available, the $F$-optimal policy can only be either $L F$ or $P\left(I, t^{I}\right)$. When $S$ is introduced, there is a wider array of options, what opens the door for improvements. From a policy point of view, this result suggests that those countries or regions in which

\footnotetext{
${ }^{20}$ Specifically, this situation is defined by $1+\rho^{2}<W<\bar{W}$ and $A>A^{*}$.
} 
standardized systems are not well developed should seriously consider the possibility to foster them since making this possibility more available for the firms could be socially desirable from several points of view.

Technically, attaining the win-win-win situation referred to in Corollary 2 requires two conditions. First, the improvement potential can only be realized if the EMS selected by the firm shifts to $S$, what requires $A$ being large enough (see Proposition 4 ). Second, the WPR cannot be either too low or too high. If it is very low, the change might be beneficial for firms, but not for society. ${ }^{21}$ On the other hand, if $W>2$, the change would reduce the social cost, but it would result in a tax increase $\left(t^{S}>t^{I}\right)$ that might increase firms' costs. $^{22}$

\section{$5 \quad$ Predictive ability and policy implications}

The aim of this section is twofold: first, we gather all our policy implications and second we review some of our predictions in the light of empirical evidence.

\section{$5.1 \quad$ Policy implications}

The main policy implications of our findings are the following. First, we find a two-fold complementarity relationship between standardized EMS and incentive policies. On the one hand, firms that adopt a standardized EMS tend, on average, to devote more resources to pollution abatement than firms that do not, but emissions will not be lower without the

\footnotetext{
${ }^{21}$ To see this, note that the difference between $t^{I}$ and $t^{S}$ decreases with $W$. If $W<1+\rho^{2}, t^{I}-t^{S}$ is very high and large firms gain by switching to $S$. But, in this range, shifting to $S$ is socially inefficient for large values of $A$ (Specifically, $A>\hat{A}$. See Proposition 3 ).

${ }^{22}$ It can be shown that if $t^{I}$ is close enough to $t^{S}$ ( $W$ not very far from 2), there can be a range of parameters where (large) firms may gain by shifting to $S$ although this change involves a tax increase rather than a decrease.
} 
support of adequate public incentives. On the other hand, standardized systems are more prone to be adopted under tougher environmental policies.

Second, the voluntary nature of EMS adoption implies that, when designing public environmental policy, the government should pay attention, not only to the impact on the level of abatement effort, but also on the EMS adoption decision. This double effect introduces the possibility of a conflict between firm's and regulator's interests. As a consequence, it could be optimal for the planner to choose a suboptimal value for the tax rate in order to induce a change in the adoption decision.

Third, $S$-adoption is more likely for mature and well established firms facing a lower level of technological uncertainty. Moreover, there is a minimum threshold on taxes below which firms would not be willing to adopt a standardized EMS. This threshold entails an endogenous set-up cost that will typically hinder small or newcomer firms from adopting $S$. Once we take the optimal behavior of the planner into account, we also get that large or highly pollutant firms are more prone to adopt standardized systems, what could result in overadoption and the other way around for small firms.

This bigger tendency of big polluters to adopt standardized systems suggests a link between EMS adoption and corporate social responsibility (CSR) or environmental commitment (in this respect see, for example, Pedersen 2007). To what extent the adoption of EMAS or ISO 14001 can be taken as a signal of environmental or social responsibility? Although $S$ adopting firms tend, on average, to abate more and pollute less, this connection is not necessarily motivated by a stronger environmental commitment, as it can be explained as the result of a cost-minimizing behavior. Indeed, we get that the adoption of standardized EMS by mature and big (or highly pollutant) firms can be easily explained in terms of managerial efficiency gains and cost saving and, as a matter of fact, big firms 
might adopt $S$ more often than it is socially optimal. On the contrary, $S$-adoption can be seen as a more credible signal of social responsibility when it is observed in small or new firms, for which the cost saving effect is much weaker.

And the fourth policy implication is that, under some circumstances, introducing the possibility to adopt a standardized EMS can be a particularly good news since both the firm and the society might get better-off, with less pollution even at a lower tax rate. This can be a relevant policy warning for those countries or regions in which $S$ systems are still not well established.

\subsection{Predictions and connections with empirical evidence}

Our theoretical predictions are consistent with empirical evidence in some respects. As a first connection, empirical evidence reveals that one of the most common motivators for adopting $S$ is to ensure environmental regulation compliance. For example, in Morrow and Rondinelli (2002) four out of five large German energy companies interviewed reported that regulatory compliance and legal certainty were primary motivators. This evidence is consistent with our findings in the sense that a more demanding regulation (in our framework, a higher value of $t$ ) provides more incentives to adopt $S$.

Proposition 1 states that those firms adopting a standardized EMS tend, on average, to make more abatement effort. A similar finding has been made in some empirical works. For example, Anton et al. (2004) find that the adoption of a more comprehensive EMS has a significant negative impact on the intensity of toxic releases. Johnstone et al. (2007) conclude that the presence of an EMS have a significant positive impact on environmental performance. Both Anton et al. (2004) and Johnstone et al. (2007) also identify in empirical terms the two effects reported in Section 4: a marginal effect in the determination 
of the abatement effort and a qualitative or discrete effect on the adoption decision.

Proposition 1 also states that this higher abatement effort results in lower (expected) emissions only if the incentives provided by the public environmental policy are strong enough, what suggests a complementarity between standardized systems and environmental economic policies. Such complementarity is reinforced by the fact that standardized systems are more prone to be adopted under tough public policies. A complementarity relationship between the adoption of standardized EMS and environmental policy has also been empirically demonstrated in some studies. For example, Arimura et. al. (2008) show that "regulations do not significantly weaken the effect of ISO 14001. This finding confirms the relevance of concurrent use of traditional policy instruments and the voluntary approach" (p. 294). Blackman and Guerrero (2011) find that regulatory fines spur certification and, therefore, command-and-control regulation is a key driver of participation in ISO 14001. Johnstone et al. (2007) conclude that some (general purpose) environmental policies have a positive influence on the decision to introduce an EMS.

According to Proposition 2, standardized systems tend to be subject to an endogenous adoption cost higher than that of informal systems. The existence of such an adoption costs is well documented empirically. See, for example, Bansal and Bogner (2002) quoted in the introduction. It is natural to conclude that such adoption cost will typically discourage small firms from adopting a standardized EMS, which suggests a positive correlation between firm's size and $S$-adoption. Proposition 2 also suggests that a standardized EMS is more likely to be voluntarily adopted by well established firms that are subject to a lower level of uncertainty (as measured by $\rho$ ). In several empirical studies, such as those by Nakamura et al. (2001), Bansal and Bogner (2002), Grolleau et al. (2007) and Blackman and Guerrero (2011), it has also been reported that there is a positive correlation between 
size (as proxied by BAU emissions) and $S$-adoption. Our results are also consistent with this result although it is fair to acknowledge that, in our model, this positive relationship between the size of firms and their tendency to adopt a standardized EMS arises once we assume that the planner behaves optimally when designing the environmental policy.

\section{Conclusions and guidelines for future research}

We have developed a model where a policy maker gives incentives to firms to reduce pollution and firms, in turn, offer some internal incentive scheme to the environmental manager. A standardized EMS increases the control that the firm has over its internal abatement processes but it introduces some degree of rigidity. The advantage of an informal system is the ability to make quicker decisions without being constrained by a established protocol, but this comes at the cost of giving up some internal control. This model allows us to rationalize some empirical features of EMS adoption.

We have intentionally built a very simple model by including several assumptions, the relaxation of which might result in promising extensions. Although a fully-fledged analysis of any of these extensions entails technical challenges that are beyond the scope of this paper, a brief discussion seems relevant.

Firstly, we have assumed a risk-neutral agent endowed with a limited liability constraint, which makes incentive provision costly and, as noted by several authors, the implications of this element are economically similar to the existence of risk-aversion. ${ }^{23}$ To check this parallelism in our framework, it is possible to build a version of the model with a riskaverse agent. So, we have explored the mean-variance approach by assuming that the

\footnotetext{
${ }^{23}$ See Sappington (1983), for a leading article, or Laffont and Martimort (2009), for a more comprehensive discussion.
} 
agent's preferences can be represented by a mean-variance utility function. ${ }^{24}$ We conclude that the optimal behavior of the manager as defined by the ICC is the same as above but one difference arises at the participation constraint (PC) because, under risk aversion, the manager must be compensated for risk taking, which entails an additional cost for effort provision that implies an inefficient provision of effort, the same that happened in our benchmark model, although the reason is different. ${ }^{25}$ Summing up, our approach is qualitatively similar to assuming that the agent is risk averse with a particular degree of risk aversion since, in both cases, the asymmetric information problem entails a distortion in the optimal level of effort. The difference arises in the source of the distortion: in the risk-averse case incentives are distorted to reduce the risk-taking compensation whereas in our case incentives are distorted to avoid paying extra rents. The most promising question to be tackled in this line is a careful sensitivity analysis of the risk aversion coefficient.

Secondly, we have deliberately disregarded production. The simplest way to include output in our framework is to assume that production and abatement are separable decisions, the former being taken by the firm and the latter by the manager, while production and pollution are linked by assuming a constant pollution intensity in the absence of abatement. ${ }^{26}$ In this new setting, optimal abatement effort remains unchanged both under $S$ and under $I$, and so does the firm's adoption decision, while, due to separability, the production decisions are the same regardless the EMS adopted. The most important issue affects optimal taxation because of the negative effect of taxes on production. Now the firm has an additional instrument to reduce the tax bill: not only she can increase abatement but

\footnotetext{
${ }^{24} V=E(w)-\frac{r}{2} \operatorname{var}(w)-C(e), r$ being the Arrow-Pratt risk aversion coefficient.

${ }^{25}$ It can be shown that there exists one value for the risk aversion coefficient such that the optimal bonus $b$ is the same in both approaches.

${ }^{26}$ Specifically, assume that the laissez-faire emissions are $A(q)=\alpha q$, where $\alpha$ is the pollution intensity coefficient an $q$ is output.
} 
also she can reduce production. Nonetheless, the effects of all the relevant parameters $(\delta$, $c, \mu, \sigma^{2}$ and $\gamma$ ) on the optimal tax are qualitatively the same. A complete analysis of this extension would involve considering the effect on output variation on consumers' surplus, which is not present in our model.

We have also assumed a linear wage contract under $I$. As it is well known in the literature, the curvature of the optimal contract depends on the attitude of the agents to risk and so a linear contract is not optimal in general terms (see e.g. Holmstrom 1979). Some authors have shown that linear contracts are optimal in a number of settings (see Holmstrom and Milgrom, 1987 or Bose, Pal and Sappington, 2011) but our purpose is not to design a fully optimal contract, but to choose a simple pattern that captures the introduction of incentives in a more or less standard and realistic way. Since the planner anticipates the firm's behavior, inevitably, the linearity of the contract matters to determine the optimal tax policy, but we also leave a complete characterization of optimal contracts for future work.

It is also worthwhile to note that, when considering the costs of implementing a $E M S$, we have focused just on labor costs. A thorough inclusion of all the costs could affect the results. For example, a standardized EMS typically involves costly audits which are not present in the cases of an informal EMS.

\section{References}

Aghion, P., and J. Tirole (1997) Formal and real authority in organizations. Journal of political economy, 105: 1-29.

Alonso-Paulí, E. and D. Pérez-Castrillo (2012) Codes of Best Practice in Competitive 
Markets for Managers. Economic Theory, 49:113-141

Ambec, S., and P. Barla (2002) A theoretical foundation of the Porter hypothesis. Economics Letters, 75: 355-360.

Anton, W.R.Q, G. Deltas, and M. Khanna (2004) Incentives for environmental selfregulation and implications for environmental performance. Journal of Environmental Economics and Management 48: 632-654.

Arimura, T., A. Hibiki and H. Katayama (2008) Is a Voluntary Approach an Effective Environmental Policy Instrument? A Case for Environmental Management Systems. Journal of Environmental Economics and Management 55: 281-295.

Baker (1992). Incentive Contracts and Performance Measurement. Journal of Political Economy, Vol. 100, 3: 598-614.

Bansal, P. and W. C. Bogner (2002) Deciding on ISO 14001:Economics, Institutions, and Context. Long Range Planning, 35 (2002) 269-290

Blackman, O. and S. Guerrero (2011) What drives voluntary eco-certification in Mexico? Journal of Comparative Economics. Forthcoming.

Boiral, O. (2007) Corporate Greening through ISO 14001: A Rational Myth? Organization Science 18(1): 127-146.

Bose, A., Pal, D., and Sappington, D. E. (2011). On the performance of linear contracts. Journal of Economics \& Management Strategy, 20(1), 159-193.

Chang, E.S.W. and S.C.K. Wong (2006) Motivations for ISO 14001 in the hotel industry. Tourism Management 27(3): 481-492. 
Demougin, D., and Fluet, C. (1998). Mechanism sufficient statistic in the risk-neutral agency problem. Journal of Institutional and Theoretical Economics, 154, 622-639.

Demougin, D., and Fluet, C. (2001a). Ranking of information systems in agency models: an integral condition. Economic Theory, 17(2), 489-496.

Demougin, D., and Fluet, C. (2001b). Monitoring versus incentives. European Economic Review, 45(9), 1741-1764.

Dessein, W. (2002). Authority and communication in organizations. The Review of Economic Studies, 69(4), 811-838.

Escapa-González, C. (2004) Motivations and Barriers of Implementing an EMS in Spanish Organizations. Master Thesis. School of Environmental Sciences. University of East Anglia.

Fagart, M. C., and Sinclair-Desgagné, B. (2007). Ranking contingent monitoring systems. Management Science, 53(9), 1501-1509.

Florida R. and D. Davidson (2001) Gaining from Green Management: Environmental Management Systems inside and Outside the Factory. California Management Review 43(3): $64-84$.

Gabel, H.L. and B. Sinclair-Desgagne (1993) Managerial Incentives and Environmental Compliance. Journal of Environmental Economics and Management 24(3): 229-240.

Goldsmith, P.D., and R. Basak (2001) Incentive Contracts and Environmental Performance Indicators. Environmental and Resource Economics 20: 259-279.

Grolleau, G., N. Mzoughi and A. Thomas (2007) What drives agrifood firms to register for an Environmental Management System? European Review of Agricultural Economics 
$34(2): 233-255$.

Helfand, B.E., P. Berck and T. Maull (2003) The Theory of Pollution Policy. Chapter 6 in Mäler, K.G. and J.R. Vincent (eds.) Handbook of Environmental Economics, Vol I. North Holland.

Holmstrom, B. (1979) Moral hazard and observability. The Bell Journal of Economics 10: 74-91.

Holmstrom, B., \& Milgrom, P. (1987) Aggregation and linearity in the provision of intertemporal incentives. Econometrica: Journal of the Econometric Society, 303-328.

Honkasalo, A. (1998) The EMAS Scheme: a Management Tool and Instrument of Environmental Policy. Journal of Cleaner Production 6: 119-128.

ISO 14001 (1996) Environmental management systems - specification with guidance for use. London: BSI.

Jensen, M. C., and W.H. Meckling (1992) Specific and general knowledge, and organizational structure. Contract Economics, Lars Werin and Hans Wijkander, eds. Blackwell, Oxford: pp. 251-274.

Johnstone, N., M, Glachant, C. Serravalle, N. Riedinger and P. Scapecchi (2007) 'Many a slip 'twixt the cup and the lip': direct and indirect public policy incentives to improve corporate environmental performance. In Johnstone, N. (ed.) Environmental Policy and Corporate Behaviour. OECD. Edward Elgar.

Johnstone, N. and J. Labonne (2009) Why Do Manufacturing Facilities Introduce Environmental Management Systems? Improving and/or Signaling Performance. Ecological Economics 68: 719-730. 
Kim, S. K. (1995) Efficiency of an Information System in an Agency Model. Econometrica, 63(1): 89-102.

Laffont, J. J., \& Martimort, D. (2009). The theory of incentives: the principal-agent model. Princeton University Press.

Morrow, D. and D. Rondinelly (2002) Adopting Corporate Environmental Management Systems: Motivations and Results of ISO 14001 and EMAS Certification. European Management Journal 20(2): 159-171.

Nakamura, M., T. Takahashi and I. Vertinsky (2001) Why Japanese Firms Choose to Certify: A Study of Managerial Responses to Environmental Issues. Journal of Environmental Economics and Management 42: 23-52.

Pedersen, E.R. (2007) Perceptions of Performance: How European Organizations Experience EMAS Registration. Corporate Social Responsibility and Environmental Management 14: 61-73.

Prendergast, C. (2002). The Tenuous Trade-off between Risk and Incentives. The Journal of Political Economy, 110(5): 1071-1102.

Raith, M. (2008). Specific knowledge and performance measurement. The RAND Journal of Economics, 39(4): 1059-1079.

Rondinelli, D.A. and G. Vastag (1996) International Environmental Management Standards and Corporate Policies: An Integrative Framework. California Management Review 39(1): 106-122.

Sappington, D. (1983). Limited liability contracts between principal and agent. Journal of economic Theory, 29(1), 1-21.. 
Sinclair-Desgagné, B. and H.L. Gabel (1997) Environmental Auditing in Management Systems and Public Policy. Journal of Environmental Economics and Management 33: 331-346.

Stein, J. C. (2002). Information production and capital allocation: Decentralized versus hierarchical firms. The Journal of Finance, 57(5): 1891-1921.

University of North Carolina and Environmental Law Institute (UNC-ELI) (2001) Drivers, Designs and Consequences of Environmental Management Systems. Environmental Law Institute, Washington D.C.

Weitzman, M. L. (1974). Prices vs. quantities. The review of economic studies, 477-491.

\section{Appendix 1: General characterization of the F- optimal policy}

Proposition 4 Let $\bar{W} \equiv \sqrt{\frac{2\left(1+\rho^{2}\right)}{1-\rho^{2}}}$. Under Assumption 1 the F-optimal policy is characterized as follows:

\begin{tabular}{|c|c|c|c|}
\hline & when $W<\bar{W}$ & \multicolumn{2}{|c|}{ when $W \geq \bar{W}$} \\
\hline $\mathcal{P}^{L F}$ & If $A \leq \underline{A}_{I}$ & & \\
\hline $\mathcal{P}\left(I, t^{I}\right)$ & If $\underline{A}_{I} \leq A \leq \min \left\{A^{*}, A^{I}\right\}$ & $\mathcal{P}^{L F}$ & If $A \leq A^{S} / 2$ \\
\hline $\mathcal{P}\left(I, t^{*}\right)$ & If $A^{*} \geq A>A^{I}$ & $\mathcal{P}\left(S, t^{*}\right)$ & If $A^{S} \geq A>A^{S} / 2$ \\
\hline $\mathcal{P}\left(S, t^{*}\right)$ & If $A^{S} \geq A>A^{*}$ & $\mathcal{P}\left(S, t^{S}\right)$ & If $A \geq A^{S}$ \\
\hline $\mathcal{P}\left(S, t^{S}\right)$ & If $A \geq \max \left\{A^{*}, A^{S}\right\}$ & & \\
\hline
\end{tabular}


with indifference when the conditions hold with "=", where $A^{*}$ is a unique threshold defined when $A>\underline{A}^{F}$ and $W<\bar{W}$, such that the $F$-optimum involves $E M S=S$ if $A>A^{*}$ and $E M S=I$ if $A<A^{*}$

\section{Appendix 2: Proofs}

Proof of Proposition 1 From Lemma 2 we know that $e_{S}=\frac{t \mu}{c} \geq \frac{t_{s} \mu}{c}$ is known with certainty. $E e_{I}$ depends on $t$. Using Lemma 1, if $\underline{t}_{I}<t<2 \underline{t}_{I}, e_{I}=\underline{t}_{I} \underline{x} \Longrightarrow E e_{I}=\underline{t}_{I} \underline{\mu} \frac{\mu}{c}<e_{S}$ and if $t>2 \underline{t}_{I}, e_{I}=\frac{t x}{2 c}$ and $E e_{I}=\frac{t \mu}{2 c}<\frac{t \mu}{c}$. This proves the first part. To prove the second, note that under $S$ we have $E\left(P_{S}\right)=A-t \frac{\mu^{2}}{c}$. Regarding $I$ we need to check two cases:

1. If $t<2 \underline{t}_{I}, E\left(P_{I}\right)=A-\sqrt{\frac{2\left(\mu^{2}+\sigma^{2}\right) \underline{\underline{U}}}{c}}$ and we get $E\left(P_{S}\right) \leq E\left(P_{I}\right) \Longleftrightarrow t \geq$ $\frac{c}{\mu^{2}} \sqrt{\frac{2\left(\mu^{2}+\sigma^{2}\right) \underline{\underline{U}}}{c}}=\frac{1}{\mu} \sqrt{2 c \underline{U}\left(1+\rho^{2}\right)}=\underline{t}_{S} \sqrt{\left(1+\rho^{2}\right)}=t^{e}$. By direct comparison, $t^{e}<2 \underline{t}_{I} \Longleftrightarrow$ $\rho<1$. So, if $\rho>1, E\left(P_{S}\right)>E\left(P_{I}\right)$ for any $t \in\left[\underline{t}_{S}, 2 \underline{t}_{I}\right]$.

2. If $t>2 \underline{t}_{I}, E\left(P_{I}\right)=A-\frac{t}{2 c}\left(\mu^{2}+\sigma^{2}\right)$ and we get $E\left(P_{S}\right) \leq E\left(P_{I}\right) \Longleftrightarrow 2 \mu^{2} \geq$ $\mu^{2}+\sigma^{2} \Longleftrightarrow \rho \leq 1$. If $\rho<1$ we also have $t^{e}<2 \underline{t}_{I}<t_{\text {. }}$

Proof of Proposition 2 We compare $E C_{I}$ and $E C_{S}$ (from Lemma 1 and Lemma 2). When $\underline{t}_{I}<t<2 \underline{t}_{I}$, (i) at $t=\underline{t}_{I}, E C_{I}\left(\underline{t}_{I}\right)<E C_{S}\left(\underline{t}_{I}\right)$ and (ii) $E C_{I}$ is linear and $E C_{S}$ is strictly concave in $t$ in $\left(\underline{t}_{I}, 2 \underline{t}_{I}\right)$. Both functions can cross no more than once. At $t=2 \underline{t}_{I}$ we get

$$
E C_{S}\left(2 \underline{t}_{I}\right) \leq E C_{I}\left(2 \underline{t}_{I}\right) \Longleftrightarrow 2 \underline{\underline{t}}_{I}^{2} \frac{\mu^{2}}{2 c}>2 \underline{t}_{I} \sqrt{\frac{2\left(\sigma^{2}+\mu^{2}\right) \underline{U}}{c}}-\underline{U} \Longleftrightarrow \rho<\frac{1}{\sqrt{3}}=\frac{\sqrt{3}}{3}
$$

and so both function cross in the $\left(\underline{t}_{I}, 2 \underline{t}_{I}\right)$ range iff $\rho<\frac{\sqrt{3}}{3}$. Under $\rho<\frac{\sqrt{3}}{3}, E C_{S}(t)<$ 
$E C_{I}(t)$ if and only if

$t^{2} \frac{\mu^{2}}{2 c}>t \sqrt{\frac{2\left(\sigma^{2}+\mu^{2}\right) \underline{U}}{c}}-\underline{U} \Longleftrightarrow t>t^{*} \equiv \frac{\sqrt{2 c \underline{U}}}{\mu^{2}}\left[\sqrt{\sigma^{2}+\mu^{2}}+\sqrt{\sigma^{2}}\right]=\sqrt{2 c \underline{U}}\left[\sqrt{\rho^{2}+1}+\rho\right]$.

If $\rho>\frac{\sqrt{3}}{3}, E C_{I}$ and $E C_{S}$ cannot cross for $t^{*}<2 \underline{t}_{I}$. So, if the crossing point exists it must be such that $t^{*}>2 \underline{t}_{I}$. Indeed,

$E C^{S}<E C^{I} \Longleftrightarrow \frac{t^{2}\left(\sigma^{2}+\mu^{2}\right)}{4 c}<\frac{t^{2} \mu^{2}}{2 c}-\underline{U} \Longleftrightarrow t>t^{*} \equiv 2 \sqrt{\frac{c \underline{U}}{\mu^{2}-\sigma^{2}}}>2 \underline{t}_{I} \Longleftrightarrow \rho>\frac{\sqrt{3}}{3}$

which also implies that if $\rho \geq 1$ (or, equivalently, $\sigma^{2}>\mu^{2}$ ) $E C_{S}>E C_{I} \forall t$

Proof of Corollary 1 According to Proposition 1, $\rho<1$ and $t \geq t^{*}$ must hold. Since no firm adopts $S$ if $\rho \geq 1$ (Proposition 2), it is left to check if $t^{e}<t^{*}$. When $\rho<\frac{\sqrt{3}}{3}, t^{e}<$ $t^{*} \Longleftrightarrow \frac{1}{\mu} \sqrt{2 c \underline{U}\left(1+\rho^{2}\right)}<\frac{\sqrt{2 c \underline{U}}}{\mu}\left[\rho+\sqrt{\rho^{2}+1}\right] \Longleftrightarrow \frac{\sqrt{\left(1+\rho^{2}\right)}}{\rho+\sqrt{1+\rho^{2}}}<1 \Longleftrightarrow \rho>0$, while, when $\rho \geq \frac{\sqrt{3}}{3}, t^{e}<t^{*} \Longleftrightarrow \frac{1}{\mu} \sqrt{2 c \underline{U}\left(1+\rho^{2}\right)}<\frac{2}{\mu} \sqrt{\frac{c \underline{U}}{\left(1-\rho^{2}\right)}} \Longleftrightarrow\left(1-\rho^{2}\right)\left(1+\rho^{2}\right)<2 \Longleftrightarrow \rho \geq-1$ which always holds.

\section{Proof of Lemma 3}

Proposition 2 and the definitions of $t^{S}$ and $t^{I}$ determine that, under Assumption 1, $\mathcal{P}\left(S, t^{S}\right)$ is implementable iff $t^{S} \geq t^{*}$ and $\mathcal{P}\left(I, t^{I}\right)$ is implementable iff $t^{*} \geq t^{I}$. Regarding $\mathcal{P}\left(S, t^{S}\right)$, we have $t^{*}>\underline{t}_{S}$, what implies that, if $\mathcal{P}\left(S, t^{S}\right)$ is implementable, then $t^{S}=$ $\frac{A c \delta}{\delta\left(\mu^{2}+\sigma^{2}\right)+c}$. Using the expressions for $t^{S}$ and $t^{*}$ we have $t^{S} \geq t^{*} \Leftrightarrow A \geq A^{S}$, where $A^{S} \equiv 2 \sqrt{\frac{\underline{U}}{c\left(\mu^{2}-\sigma^{2}\right)}}\left[\left(\mu^{2}+\sigma^{2}\right)+\frac{c}{\delta}\right] . \quad$ Regarding $\mathcal{P}\left(I, t^{I}\right)$, we need $A \geq \underline{A}_{I}$ to ensure that $I$ is preferred to LF. If $A \geq \underline{A}_{I}$ there are two relevant cases (whether $A \gtrless \underline{2}_{I}$ ). If $A \geq \underline{2 A}_{I}$, we have $t^{*} \geq t^{I} \Longleftrightarrow A \leq A^{I}$, where $A^{I} \equiv \sqrt{\frac{\underline{U}}{c\left(\mu^{2}-\sigma^{2}\right)}}\left[\frac{\gamma}{\left(\mu^{2}+\sigma^{2}\right)}+\frac{c}{\delta}\right]$. If $A<2 \underline{A}_{I}$, $t^{I} \leq t^{*}$ always holds because of Assumption 1. So, $\underline{A}_{I} \leq A \leq 2 \underline{A}_{I}$ is a sufficient condition 
for $\mathcal{P}\left(I, t^{I}\right)$ to be implementable. Under Assumption $1,2 \underline{A}_{I} \leq A^{I}$ always holds and so $\underline{A}_{I} \leq A \leq 2 \underline{A}_{I}$ is necessary and sufficient

Lemma 4 Assume $A \geq \underline{A}^{F}$. The tax rate associated to the F-optimum, $\hat{t}$, can only be either $t^{S}, t^{I}$ or $t^{*}$. Moreover, if $t^{S} \neq t^{I}$, the following statements hold:

$$
\begin{array}{ll}
\text { If } t^{S}<t^{*} & \hat{t} \in\left\{t^{I}, t^{*}\right\} \\
\text { If } t^{I}>t^{*} & \hat{t} \in\left\{t^{S}, t^{*}\right\} \\
\text { If } t^{S}<t^{*}<t^{I} & \hat{t}=t^{*}
\end{array}
$$

\section{Proof of Lemma 4}

When considering the adoption decision, the policy maker faces the following actual cost function:

$$
\hat{E} S C(t)= \begin{cases}E_{I} S C(t) & \text { if } t<t^{*} \\ \operatorname{Min}\left\{E_{I} S C(t), E_{S} S C(t)\right\} & \text { if } t=t^{*} \\ E_{S} S C(t) & \text { if } t>t^{*}\end{cases}
$$

Assume, by contradiction, that $t_{0}$ minimizes $\hat{E} S C(t)$ and $t_{0} \notin\left\{t^{S}, t^{I}, t^{*}\right\}$. Since $t \neq t^{*}$, by continuity, there is an interval $\left(t_{0}-\varepsilon, t_{0}+\varepsilon\right)$ where $t_{0}$ is included and $t^{*}$ is not. Therefore, $t_{0}$ can be marginally increased or reduced without inducing a change of EMS. Assume $t_{0}>t^{*}$, what implies $\hat{E} S C=E S C$ in this interval. Since $t_{0} \neq t^{S}$ (i.e., $\left.t_{0} \neq \arg \min E_{S} S C(t)\right)$ and $E_{S} S C(t)$ is a strictly convex function, at $t_{0}$ the slope of $E_{S} S C(t)$ is either strictly positive or negative, and $E_{S} S C\left(t_{0}\right)$ can be reduced either by marginally increasing or reducing $t$ without inducing a change of EMS. So, $t_{0}$ cannot minimize $\hat{E} S C(t)$. A similar argument applies if $t_{0}<t^{*}$ (what implies $\hat{E} S C\left(t_{0}\right)=E_{I} S C\left(t_{0}\right)$ ). Thus, the only candidates to 
minimize $\hat{E} S C(t)$ are $t^{S}, t^{I}$ and $t^{*}$. This proves the first part.

If $t^{S}<t^{*}, \hat{E} S C\left(t^{S}\right)=E_{I} S C\left(t^{S}\right)$ (the firm adopts $I$ ). Since $t^{S} \neq t^{I}$, at $t^{S}$, $E_{I} S C$ do not reach a minimum, and $E_{I} S C(t)$ being a strictly convex function there must be an interval $\left(t^{S}-\varepsilon, t^{S}+\varepsilon\right)$ where $t^{*}$ is not included and we can marginally decrease $E_{I} S C(t)$ by increasing or reducing $t$ without inducing a change of EMS. Therefore, $t^{S} \neq \arg \min \hat{E} S C(t)$. A similar argument proves that, if $t^{I}>t^{*}, t^{I} \neq \arg \min \hat{E} S C(t)$. Combining both arguments, if $t^{S}<t^{*}<t^{I}$, the only candidate to minimize $\hat{E} S C(t)$ is $t^{*}$

Proof of Corollary 2 Regarding costs, from Proposition 4, there are two ranges. First, $W \in\left(1+\rho^{2}, \frac{4}{3-\rho^{2}}\right)$. If $A \in\left(A^{*}, A^{S}\right)$ the $F$-optimum is $\mathcal{P}\left(S, t^{*}\right)$ and there exists $A^{* *} \in\left(A^{*}, A^{S}\right)$ such that for any $A>A^{* *}$ social costs decrease with respect to $\mathcal{P}\left(I, t^{I}\right)$. Second, $W \in\left(\frac{4}{3-\rho^{2}}, 2\right)$. For any $A \in\left(A^{*}, A^{S}\right), E_{I} S C\left(t^{I}\right)>E_{S} S C\left(t^{*}\right)$. In both ranges, if $A>A^{S} \mathcal{P}\left(t^{S}, S\right)$ is the $G$-optimum and it is implementable, what implies $E_{S} S C\left(t^{S}\right) \leq$ $E_{I} S C\left(t^{I}\right)$.

Firms become better-off if it is optimal for them to move from $I$ to $S$, i.e., $A>A^{*}$. Therefore, both the firm and the society gets simultaneously better-off if $A>A^{L}$ where $A^{L}=A^{* *}$ if $W \in\left(1+\rho^{2}, \frac{4}{3-\rho^{2}}\right)$ and $A^{L}=A^{*}$ if $W \in\left(\frac{4}{3-\rho^{2}}, 2\right)$.

Regarding emissions, there are two cases: (a) If $A>A^{S}, E P\left(S, t^{S}\right)<E P\left(I, t^{I}\right) \Longleftrightarrow$ $\frac{\mu^{2} \delta A}{\delta \theta+c}>\frac{\theta \delta A}{\delta \frac{\gamma}{\theta}+c}$ and the latter condition holds always that $W>1+\rho^{2}$. (b) if $A \in\left(A^{*}, A^{S}\right)$ using the relevant expressions we have $E P\left(S, t^{*}\right)<E P\left(I, t^{I}\right) \Longleftrightarrow A<2 \sqrt{\frac{U}{c\left(2 \mu^{2}-\theta\right)}} \frac{\delta \frac{\gamma}{\theta}+c}{\delta} \frac{\mu^{2}}{\theta}<$ $A^{S}$ where the last inequality is true when $W>1+\rho^{2}$. Regarding taxes, there are two cases: If $A>A^{S}>A^{I}$ the $F$-optimum is $\mathcal{P}\left(S, t^{s}\right)$ and it is easy to proof that $A^{S}>A^{I}$ $\Longleftrightarrow t^{S}<t^{I}$. If $A^{I}<A^{L}<A<A^{S}$ the $F$-optimum is $\mathcal{P}\left(S, t^{*}\right)$ and Lemma 3 implies $t^{*}<t^{I}$ 


\section{$9 \quad$ Appendix 3: Figures captions}

FIGURE 1: Optimal EMS for the firm

FIGURE 2: Global optimum

FIGURE 3: Conflict between firm's and social interests

FIGURE 4: Social and Private (dis)agreements

FIGURE 5: $F$-optimal policies (" $I$ to $S$ " mean that the $G$-optimum involves $I$ and the F-optimum $S$ and so on) 


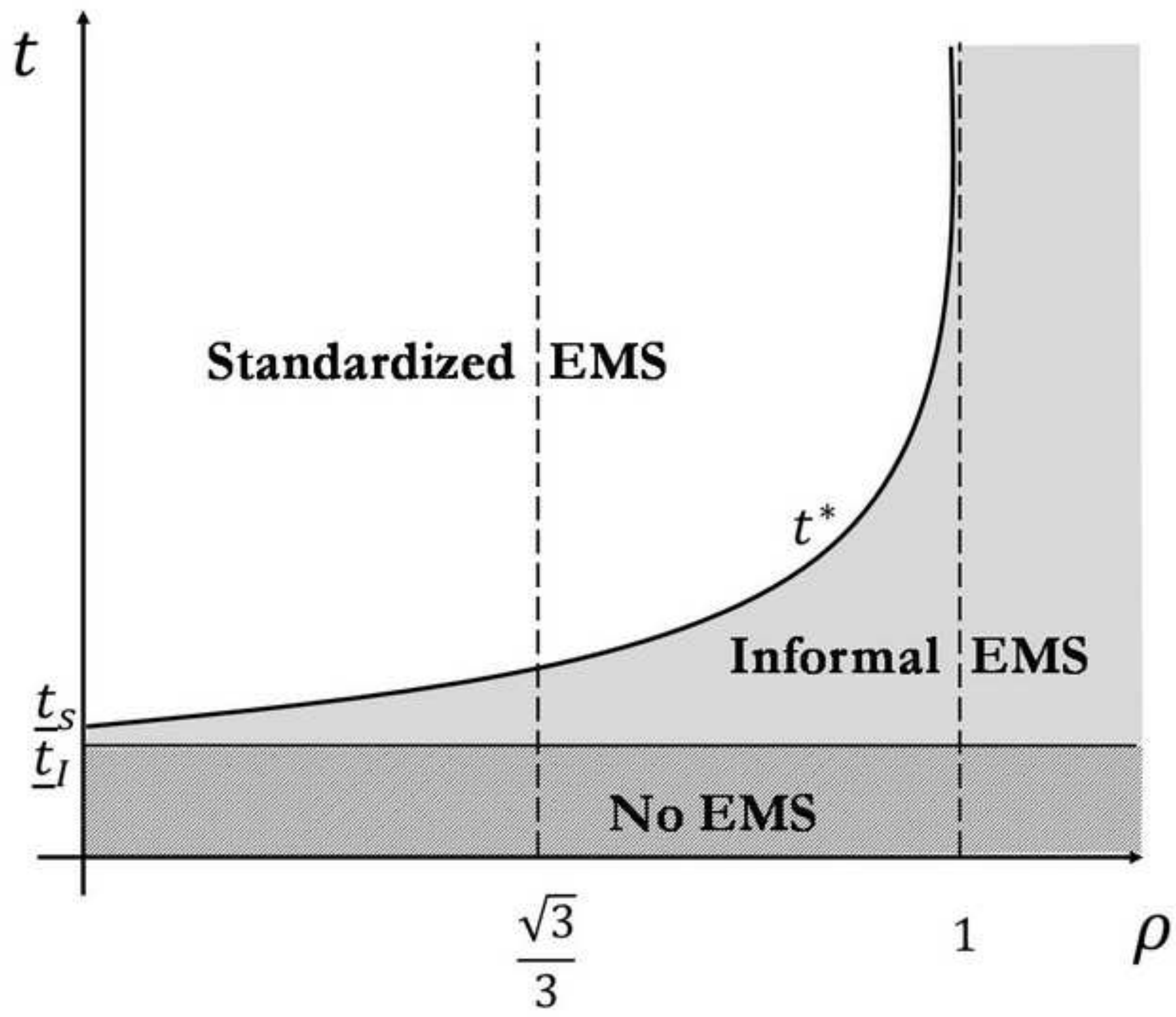


Click here to download high resolution image

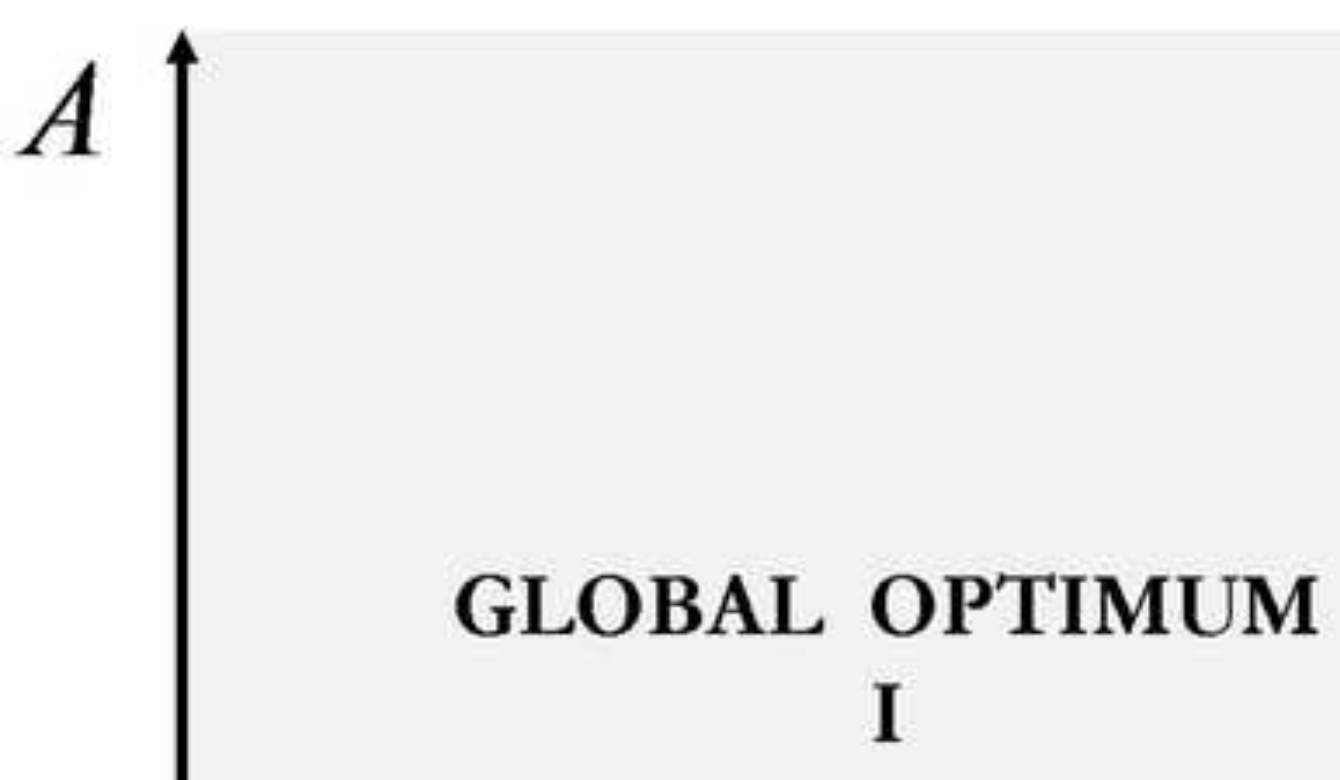

\section{GLOBAL OPTIMUM} $\mathrm{S}$

\section{GLOBAL OPTIMUM}

\section{LF}
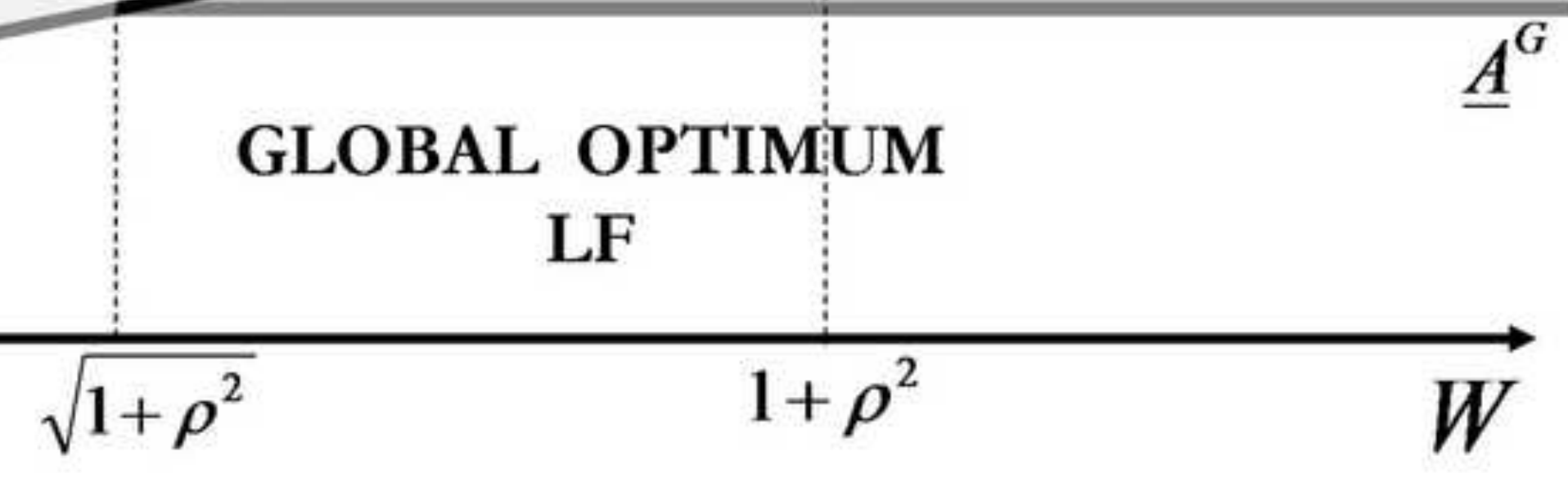


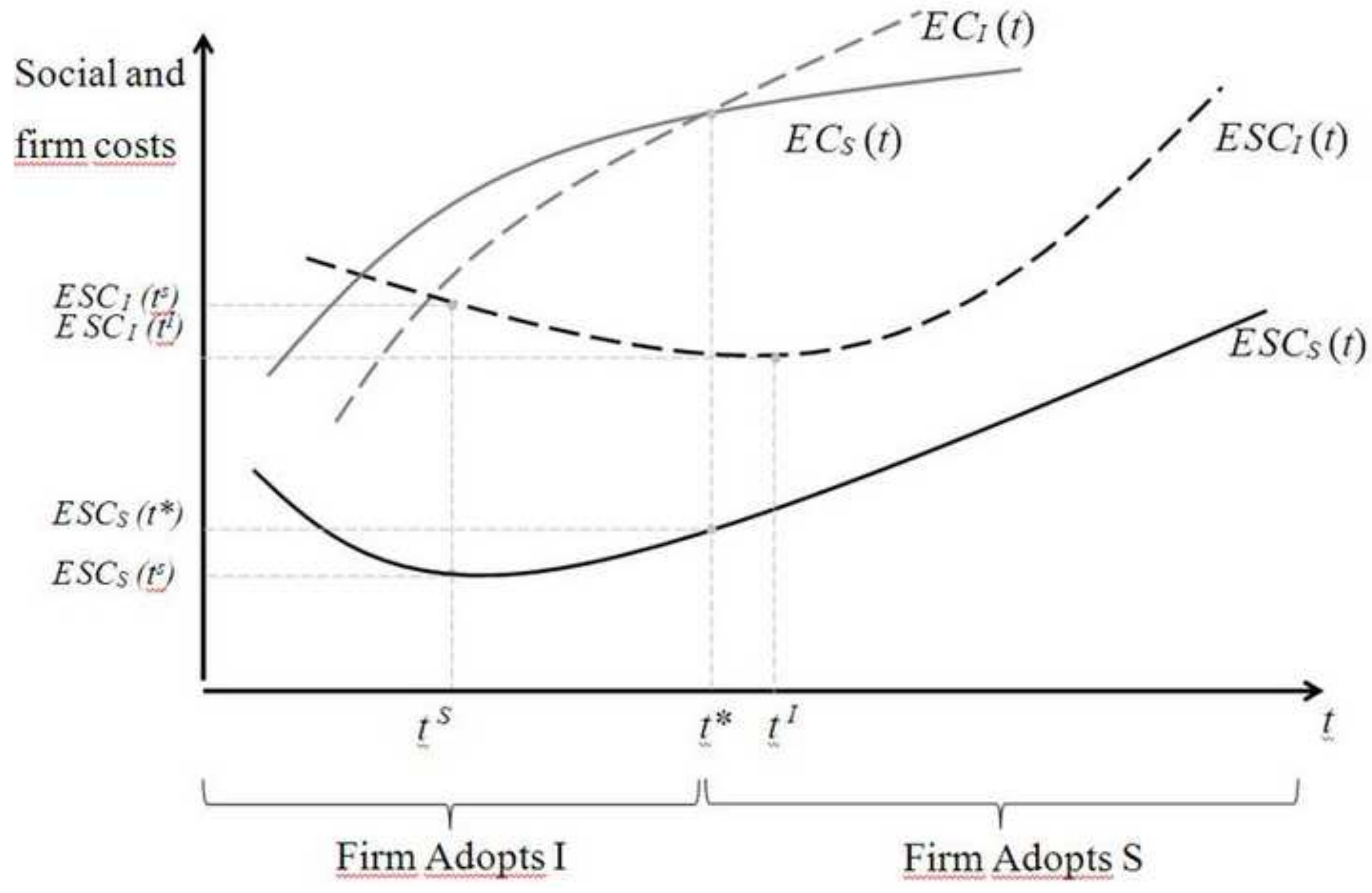


Click here to download high resolution image

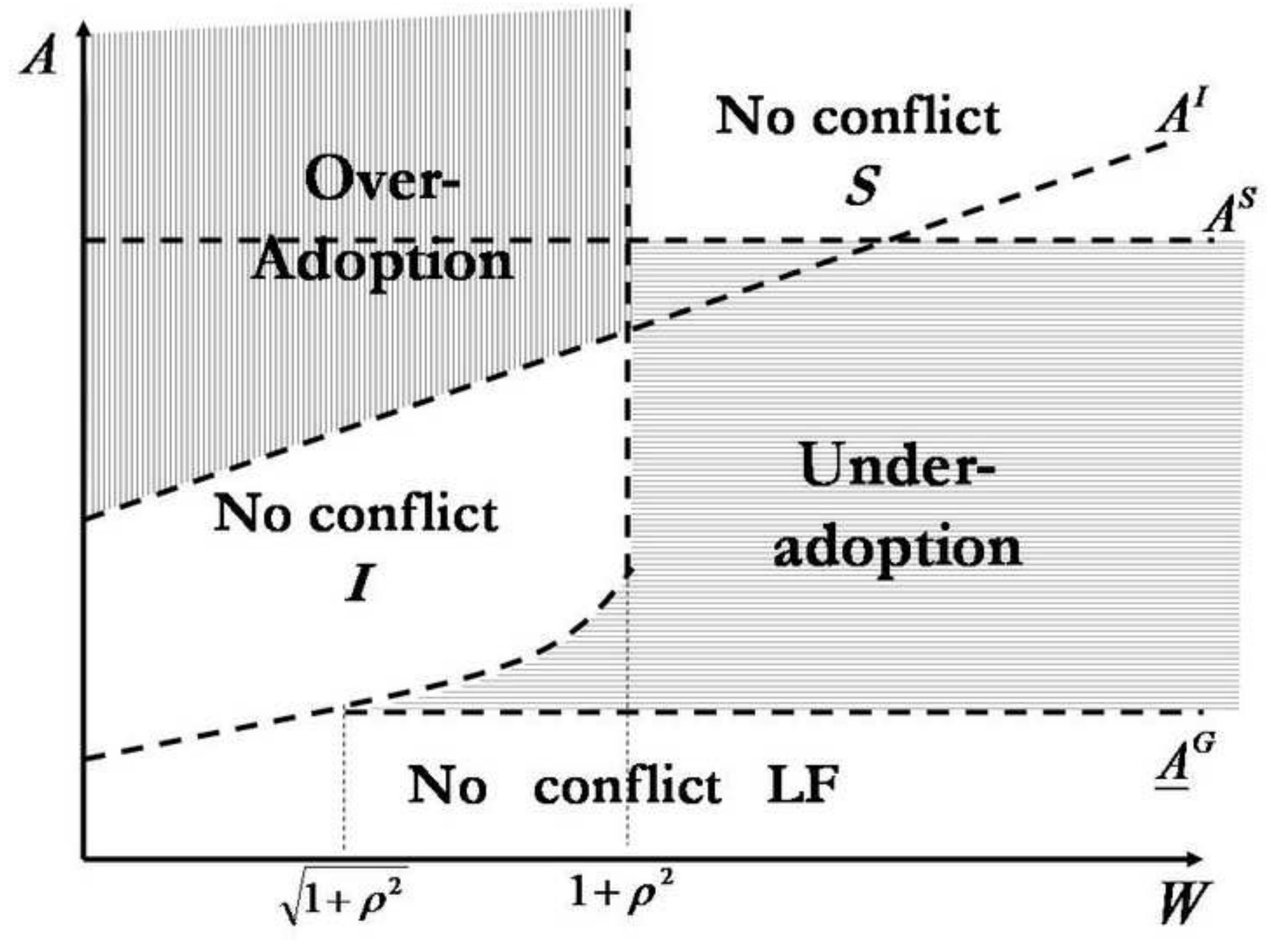

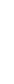
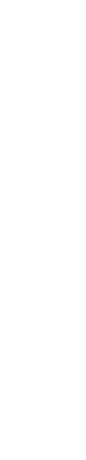


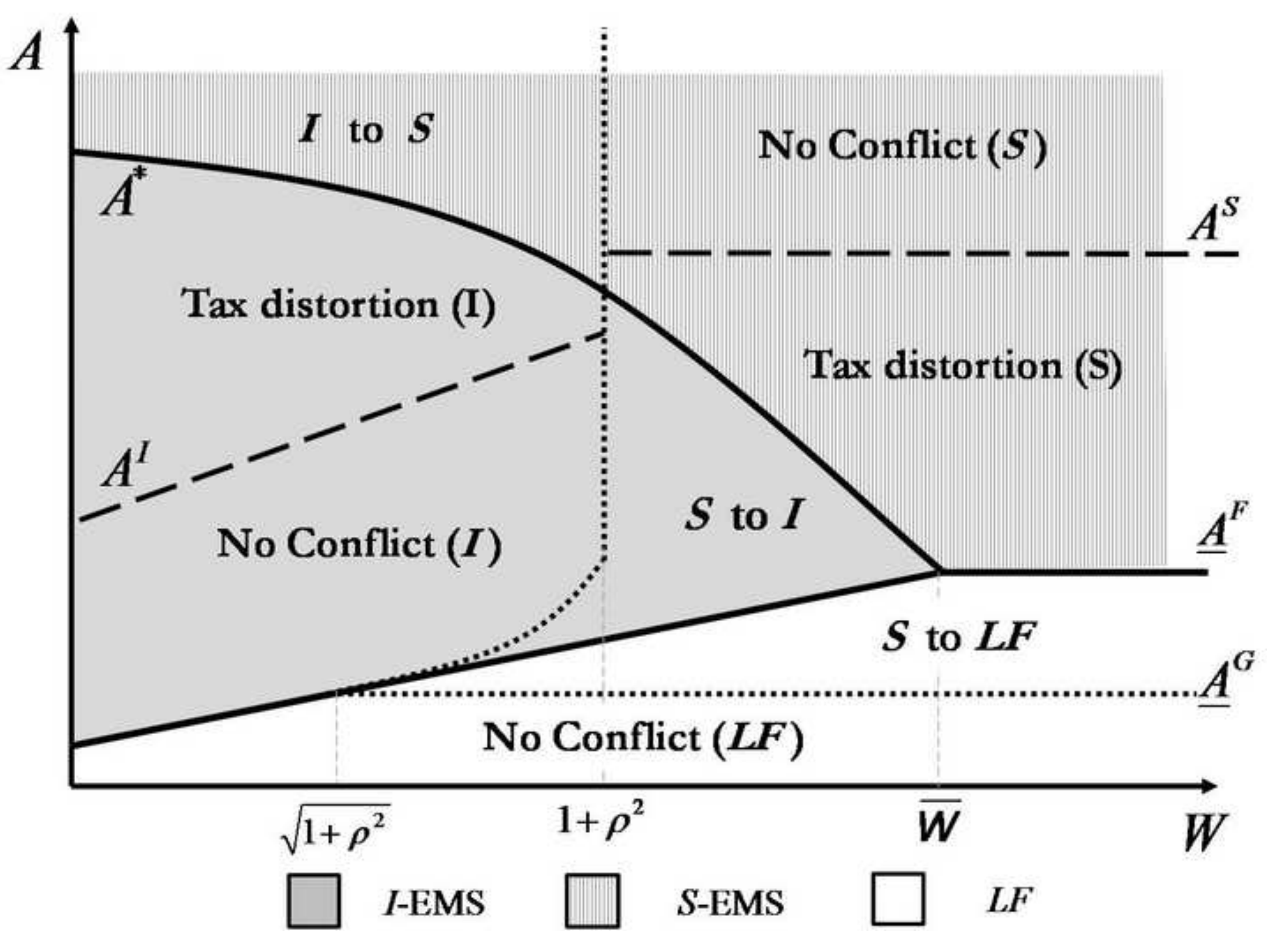




\begin{tabular}{c|cc} 
& W low & W high \\
\hline A high & Overadoption & No conflict $S$ \\
A medium & No conflict $I$ Underadoption \\
A low & \multicolumn{2}{|c}{ No conflict $L F$} \\
\hline
\end{tabular}

